\title{
Research Article \\ Pricing Equity-Indexed Annuities under Stochastic Interest Rates Using Copulas
}

\author{
Patrice Gaillardetz \\ Department of Mathematics and Statistics, Concordia University, Montreal, QC, Canada H3G 1M8 \\ Correspondence should be addressed to Patrice Gaillardetz, gaillardetz@hotmail.com
}

Received 1 October 2009; Accepted 18 February 2010

Academic Editor: Johanna Neslehova

Copyright ( 2010 Patrice Gaillardetz. This is an open access article distributed under the Creative Commons Attribution License, which permits unrestricted use, distribution, and reproduction in any medium, provided the original work is properly cited.

We develop a consistent evaluation approach for equity-linked insurance products under stochastic interest rates. This pricing approach requires that the premium information of standard insurance products is given exogenously. In order to evaluate equity-linked products, we derive three martingale probability measures that reproduce the information from standard insurance products, interest rates, and equity index. These risk adjusted martingale probability measures are determined using copula theory and evolve with the stochastic interest rate process. A detailed numerical analysis is performed for existing equity-indexed annuities in the North American market.

\section{Introduction}

An equity-indexed annuity is an insurance product whose benefits are linked to the performance of an equity market. It provides limited participation in the performance of an equity index (e.g., S\&P 500) while guaranteeing a minimum rate of return. Introduced by Keyport Life Insurance Co. in 1995, equity-indexed annuities have been the most innovative insurance product introduced in recent years. They have become increasingly popular since their debut and sales have broken the $\$ 20$ billion barrier ( $\$ 23.1$ billion) in 2004, reaching $\$ 27.3$ billion in 2005. Equity-indexed annuities have also reached a critical mass with a total asset of $\$ 93$ billion in 2005 (2006 Annuity Fact Book (Tables 7-8) from the National Association for Variable Annuities (NAVA)). See the monograph by Hardy [1] for comprehensive discussions on these products.

The traditional actuarial pricing approach evaluates the premiums of standard life insurance products as the expected present value of its benefits with respect to a mortality law plus a security loading. Since equity-linked products are embedded with various types of financial guarantees, the actuarial approach is difficult to extend to these products and often produces premiums inconsistent with the insurance and financial markets. Many attempts 
have been made to provide consistent pricing approaches for equity-linked products using financial and economical approaches. For instance, Brennan and Schwartz [2] and Boyle and Schwartz [3] use option pricing techniques to evaluate life insurance products embedded with some financial guarantees. Bacinello and Ortu $[4,5]$ consider the case where the interest rate is stochastic. More recently, Møller [6] employs the risk-minimization method to evaluate equity-linked life insurances. Young and Zariphopoulou [7] evaluate these products using utility theory ${ }^{1}$. Particularly for equity-indexed annuities, Tiong [8] and Lee [9] obtain closedform formulas for several annuities under the Black-Scholes-Merton framework. Moore [10] evaluates equity-indexed annuities based on utility theory. Lin and Tan [11] and Kijima and Wong [12] consider more general models for equity-indexed annuities, in which the external equity index and the interest rates are general stochastic differential equations.

The liabilities and premiums of standard insurance products are influenced by the insurer financial performance. Indeed, insurance companies adjust their premiums according to the realized return from their fixed income and other financial instruments as well as market pressure. Therefore, mortality security loadings underlying insurance pricing approach evolve with the financial market. With the current financial crisis, a flexible approach for equity-linked products that allows interdependency between risks should be used. Hence, we generalize the approach of Gaillardetz and Lin [13] to stochastic interest rates. Similarly to Wüthrich et al. [14], they introduce a market consistent valuation method for equity-linked products by combining probability measures using copulas. Indeed, the deterministic interest rate assumption may be adequate for short-term derivative products; however, it is undesirable to extrapolate for longer maturities as for the financial guarantees embedded in equity-linked products. Therefore, we use the approach of Gaillardetz [15] to model standard insurance products under stochastic interest rates. It supposes the conditional independence between the insurance and interest rate risks. Here, this approach is generalized to models that are based on copulas.

Similarly to Gaillardetz and Lin [13], we assume that the premium information of term life insurances, pure endowment insurances, and endowment insurances at all maturities is obtainable. We obtain martingale measures for each standard insurance product under stochastic interest rates. To this end, it is required to assume that the volatilities for standard insurance prices are given exogenously. Gaillardetz [15] provides additional structure to find an implicit volatilities for the standard insurance and annuity products. Then, the martingale probability measures for the insurance and interest rate risks are combined with the martingale measure from the equity index. These extend martingale measures are used to evaluate equity-linked insurance contracts and equity-indexed annuities in particular.

This paper is organized as follows. The next section presents financial models for the interest rates and equity index as well as insurance model. We then derive martingale measures for those standard insurance products under stochastic interest rates in Section 3. In Section 4, we derive the martingale measures for equity-linked products. Section 5 focuses on recursive pricing formulas for equity-linked contracts. Finally, we examine the implications of the proposed approaches on the EIAs by conducting a detailed numerical analysis in Section 6.

\section{Underlying Financial Models}

In this section, we present a multiperiod discrete model that describes the dynamic of a stock index and the interest rate. These lattice models have been intensively used to model stocks, stock indices, interest rates, and other financial securities due to their flexibility and 
tractability; see Panjer et al. [16] and Lin [17], for example. Moreover, as it often happens when working in a continuous framework, it becomes necessary to resort to simulation methods in order to obtain a solution to the problems we are considering. Moreover, the premiums obtained from discrete models converge rapidly to the premiums obtained with the corresponding continuous models when considering equity-indexed annuities.

\subsection{Interest Rate Model}

Similarly to Gaillardetz [15], it is assumed that the short-term ratefollows that of Black et al. [18] (BDT), which means that the short-term rate follows a lattice model that is recombining and Markovian. Particularly, the short-term rate can take exactly $t+1$ distinct values at year $t$ denoted by $r(t, 0), r(t, 1), \ldots, r(t, t)$. Indeed, $r(t, l)$ represents the short-term rate between time $t$ and $t+1$ that has made " $l$ " up moves. The short-term rate today, $r(0)$, is equal to $r(0,0)$, and in the case where $r(t)=r(t, l)$, the short-term rate at time $t+1, r(t+1)$ can only take two values, either $r(t+1, l)$ (decrease) or $r(t+1, l+1)$ (increase). We consider the short-term rate process under the martingale measure $Q$ and hence, the discounted value process $L(t, T) / B(t)$ is a martingale. $L(t, T)$ represents the price at time $t$ of a default-free, zero-coupon bond paying one monetary unit at time $T$ and $B(t)$, the money market account, represents one monetary unit $(B(0)=1)$ accumulated at the short-term rate

$$
B(t)=\prod_{i=0}^{t-1}[1+r(i)]
$$

Let $q(t, l)$ be the probability under $Q$ that the short-term rate increases at time $t+1$ given $r(t)=r(t, l)$. That is

$$
q(t, l)=Q[r(t+1)=r(t+1, l+1) \mid r(t)=r(t, l)]
$$

for $0 \leq l \leq t$, which is set to be 0.5 under the BDT model. Figure 1 describes the dynamic of the short-term rate process.

The BDT model also assumes that short-term rate process matches an array of yields volatilities $\left(\sigma_{r}(1), \sigma_{r}(2), \ldots\right)$, which is assumed to be observable from the financial market. This vector is deterministic, specified at time 0 , and each element is defined by

$$
\begin{aligned}
\sigma_{r}(t)^{2} & =\operatorname{Var}[\ln r(t) \mid r(t-1)=r(t-1, l)] \\
& =\left[0.5 \ln \left(\frac{r(t, l+1)}{r(t, l)}\right)\right]^{2}
\end{aligned}
$$

for $l=0,1, \ldots, t-1$ and $t=1, \ldots$. Hence, $r(t, l+1)$ is larger than $r(t, l)$ thus, (2.3) may be rewritten as follows:

$$
\sigma_{r}(t)=0.5 \ln \left(\frac{r(t, l+1)}{r(t, l)}\right)
$$




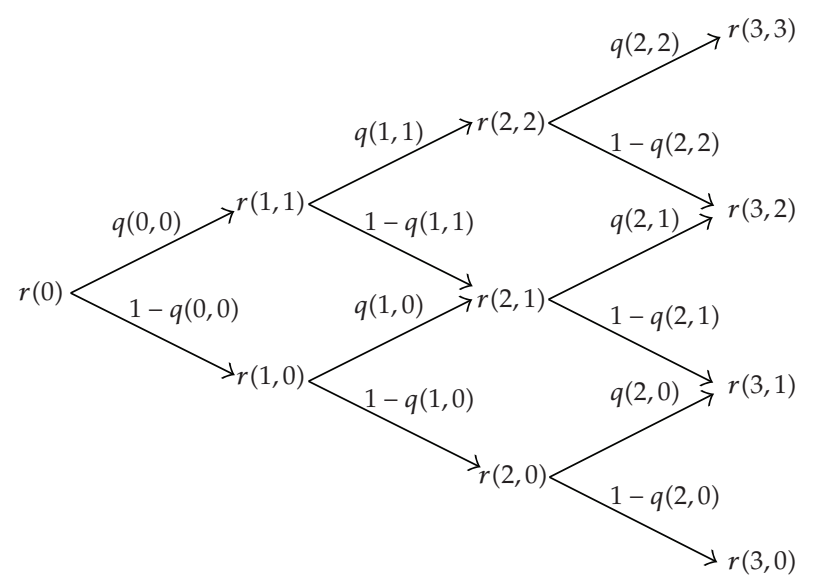

Figure 1: The probability tree of the BDT model process over 3 years.

Equation (2.4) holds for $l \in\{0,1, \ldots, t-1\}$ and leads to

$$
r(t, l)=r(t, 0)^{1-l / t} r(t, t)^{l / t},
$$

for $l=0,1, \ldots, t$. Equations (2.4) and (2.5) lead to

$$
\sigma_{r}(t)=\frac{1}{2 t} \ln \left(\frac{r(t, t)}{r(t, 0)}\right)
$$

By matching the market prices and the model prices, we have

$$
\begin{aligned}
L(0, t) & =E\left[\frac{1}{B(t)}\right] \\
& =\frac{2^{-t+1}}{(1+r(0))} \sum_{l_{1}=0}^{1} \sum_{l_{2}=l_{1}}^{l_{1}+1} \ldots \sum_{l_{t-1}=l_{t-2}}^{l_{t-2}+1} \prod_{m=1}^{t-1}\left(1+r\left(m, l_{m}\right)\right)^{-1}
\end{aligned}
$$

where $E[\cdot]$ represents the expectation with respect to $Q$. Replacing $r(t, l), l=1,2, \ldots, t-1$, in (2.7) using (2.5) leads to a system of two equations (2.6) and (2.7) with two unknowns $r(t, t)$ and $r(t, 0)$, which can be solved for all $t$.

\subsection{Index Model}

Similar to Gaillardetz and Lin [13], we suppose that each year is divided into $N$ trading subperiods of equal length $\Delta=N^{-1}$, which means that the set of trading dates for the index is $\{0, \Delta, 2 \Delta, \ldots\}$. We also assume a lattice index model such that the index process $S(k), k=$ $\Delta, 2 \Delta, \ldots$, has two possible outcomes $S(k-\Delta) d(k)$ and $S(k-\Delta) u(k)$ given $S(k-\Delta)$ for the time period $[k-\Delta, k]$, where $S(0)$ is the initial level of the index. The index level $S(k-\Delta) d(k)$ at time $k$ represents the index level when the index value goes down and $S(k-\Delta) u(k)$ represents 
the index level when the index values goes up. Since the short-term rate is a yearly process, we assume that the values $d(k)$ and $u(k)$ are constant for each year. Hence, we may write $d(k)=d(t)$ and $u(k)=u(t)$ for $k=t-1+\Delta, t-1+2 \Delta, \ldots, t$. Because of the number of trading dates per year, the time- $k$ value of the money-market account is given by

$$
B(k)=\prod_{i=\{0, \Delta, \ldots, \mathrm{k}-\Delta\}}[1+r([i])]^{\Delta},
$$

for $k=0, \Delta, 2 \Delta, \ldots$ Here, $\lfloor\cdot\rfloor$ is the floor function.

A martingale measure for the financial model needs to be determined for the valuation of equity-linked products. This martingale measures $Q$ should be such that $L(t, T) / B(t), t=$ $0,1, \ldots, T$, and $S(k) / B(k), k=0, \Delta, \ldots, \tau$, remain martingales. Note that the goal of this section is to derive the conditional distribution of the index process. Hence, the constraints imposed by the martingale discounted value process $L(t, T) / B(t)$ are to be discussed later. Let $\pi(k, l)$ be the conditional probability that the index value goes up during the period $[k-\Delta, k]$ given $r(t-1)=r(t-1, l)$, that is,

$$
\begin{gathered}
Q[S(k)=S(k-\Delta) u(t) \mid S(k-\Delta), r(t-1)=r(t-1, l)]=\pi(k, l), \\
Q[S(k)=S(k-\Delta) d(t) S(k-\Delta), r(t-1)=r(t-1, l)]=1-\pi(k, l),
\end{gathered}
$$

for $k=t-1+\Delta, t-1+2 \Delta, \ldots, t$ and $t=1,2, \ldots$ Supposing that the discounted value process $S(k) / B(k)$ is a martingale implies

$$
\pi(k, l)=\frac{(1+r(t-1, l))^{\Delta}-d(t)}{u(t)-d(t)},
$$

for $k=t-1+\Delta, t-1+2 \Delta, \ldots, t$ and $t=1,2 \ldots$ From $(2.10)$ it is obvious that $\pi(k, l)$ is constant over each year, that is, $\pi(k, l)=\pi(t, l)$ for $k=t-1+\Delta, t-1+2 \Delta, \ldots, t$. The no-arbitrage thus requires

$$
d(t)<(1+r(t-1,0))^{\Delta}, \quad(1+r(t-1, t-1))^{\Delta}<u(t),
$$

for $t=1,2, \ldots$. The previous conditions may not be respected for the BDT model when long maturity or high volatility are considered. In this case, the bounded trinomial model from Hull and White [19] would be more suitable.

Under this model, the ratio $(S(t)) /(S(t-1))$ takes $N+1$ possible values denoted $\gamma(t, i)$, $i=0,1, \ldots, N$, which are defined by

$$
\gamma(t, i)=u(t)^{i} d(t)^{N-i}, \quad i=0,1, \ldots, N .
$$

Their corresponding conditional martingale probabilities are

$$
Q\left[\frac{S(t)}{S(t-1)}=r(t, i) \mid r(t-1)=r(t-1, l)\right]=\left(\begin{array}{c}
N \\
i
\end{array}\right) \pi(t, l)^{i}(1-\pi(t, l))^{N-i},
$$

for $i=0, \ldots, N$. 


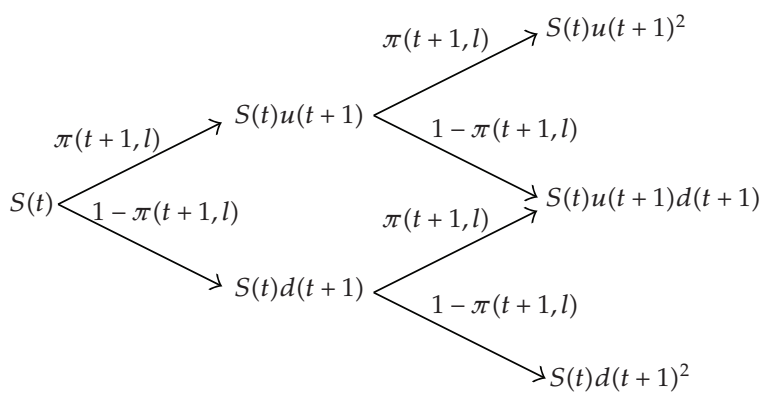

Figure 2: The probability tree of the index under stochastic interest rates over $t$ and $t+1$ when $N=2$ given $r(t)=r(t, l)$.

The model assumes the usual frictionless market: no tax, no transaction costs, and so forth. Furthermore, for practical implementation purposes, one may also use current forward rates for $r$.

Figure 2 presents the conditional index process tree under stochastic interest rates when $N=2$ for the time period $[t, t+1]$.

For notational convenience, let

$$
\mathbf{i}_{t}=\left\{i_{0}, \ldots, i_{t}\right\},
$$

which represents the index's realization up to time $t$ with

$$
S\left(t, \mathbf{i}_{t}\right)=S(0) \prod_{l=0}^{t} \gamma\left(l, i_{l}\right)
$$

for $t=0,1, \ldots$, where $\gamma\left(0, i_{0}\right)=1$.

\subsection{Insurance Models}

In this subsection, we introduce lattice models for the standard insurance products under stochastic interest rates. We will use the standard actuarial notation which can be found in Bowers et al. [20]. Let $T(x)$ be the future lifetime of insured $(x)$ of age $x$ and the curtatefuture-lifetime

$$
K(x)=\lfloor T(x)\rfloor
$$

the number of future complete years lived by the insured $(x)$ prior to death. For notational purposes, let

$$
\mathbf{l}_{t}=\left\{l_{0}, l_{1}, \ldots, l_{t}\right\}
$$

represent the realization of the short-term rate process up to time $t$ with $r(i)=r\left(i, l_{i}\right), i=$ $0,1, \ldots, t$, where $l_{0}=0$. 
For integers $t$ and $n(t \leq n)$, let $V^{(j)}\left(x, t, n, \mathbf{l}_{t}\right\}$ denote, respectively, the time- $t$ prices for the $n$-year term life insurance $(j=1), n$-year pure endowment insurance $(j=2)$, and $n$-year endowment insurance $(j=3)$ given that the short-term rate followed the path $\mathbf{l}_{t}$.

The value process $W^{(1)}\left(x, t, n, \mathbf{1}_{t-1}\right)$ of $n$-year term life insurance is defined by

$$
W^{(1)}\left(x, t, n, \mathbf{1}_{t-1}\right)= \begin{cases}\frac{B(t)}{B(K(x)+1)}, & K(x)<t \\ V^{(1)}\left(x, t, n,\left\{\mathbf{1}_{t-1}, l_{t-1}+1\right\}\right), & K(x) \geq t, r(t)=r\left(t, l_{t-1}+1\right), \\ V^{(1)}\left(x, t, n,\left\{\mathbf{1}_{t-1}, l_{t-1}\right\}\right), & K(x) \geq t, r(t)=r\left(t, l_{t-1}\right),\end{cases}
$$

with $V^{(1)}\left(x, n, n, \mathbf{1}_{n}\right)=0$. Note that $\mathbf{l}_{t}$ represents the interest rate information known by the process, but does not stand as an indexing parameter.

Similarly, define $W^{(2)}\left(x, t, n, \mathbf{1}_{t-1}\right)$ to be the value process of the $n$-year pure endowment insurance and it is given by

$$
W^{(2)}\left(x, t, n, \mathbf{1}_{t-1}\right)= \begin{cases}0, & K(x)<t, \\ V^{(2)}\left(x, t, n,\left\{\mathbf{1}_{t-1}, l_{t-1}+1\right\}\right), & K(x) \geq t, r(t)=r\left(t, l_{t-1}+1\right), \\ V^{(2)}\left(x, t, n,\left\{\mathbf{1}_{t-1}, l_{t-1}\right\}\right), & K(x) \geq t, r(t)=r\left(t, l_{t-1}\right),\end{cases}
$$

with $V^{(2)}\left(x, n, n, \mathbf{1}_{n}\right)=1$.

Finally, let $W^{(3)}\left(x, t, n, \mathbf{1}_{t-1}\right)$ denote the value process generated by the $n$-year endowment insurance

$$
W^{(3)}\left(x, t, n, \mathbf{1}_{t-1}\right)= \begin{cases}\frac{B(t)}{B(K(x)+1)}, & K(x)<t, \\ V^{(3)}\left(x, t, n,\left\{\mathbf{1}_{t-1}, l_{t-1}+1\right\}\right), & K(x) \geq t, r(t)=r\left(t, l_{t-1}+1\right), \\ V^{(3)}\left(x, t, n,\left\{\mathbf{l}_{t-1}, l_{t-1}\right\}\right), & K(x) \geq t, r(t)=r\left(t, l_{t-1}\right),\end{cases}
$$

with $V^{(3)}\left(x, n, n, \mathbf{1}_{n}\right)=1$

The processes $W^{(j)}(x, t, n), j=1,2,3$, represent the intrinsic values of the standard insurance products and are presented in Figure 3.

\section{Martingale Measures for Insurance Models}

In this section, we employ a method similar to the approach of Gaillardetz [15] to derive a martingale probability measure for each of the value processes introduced in the last section. Gaillardetz [15] derives these martingale measures under conditional independence assumptions. Here, we relax this assumption by using copulas to describe 


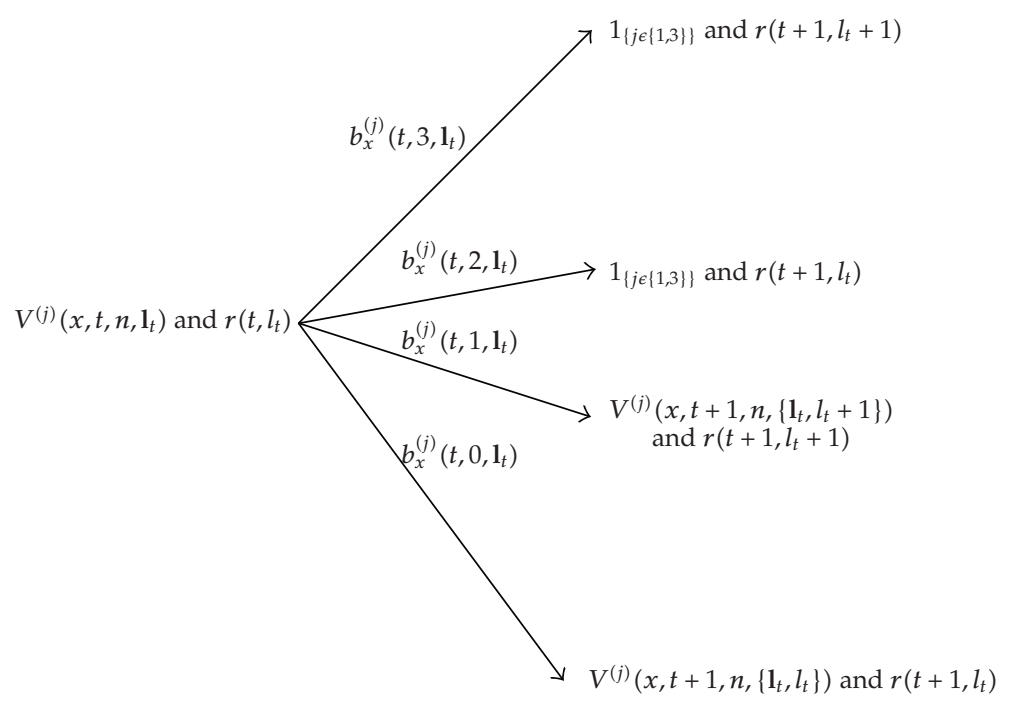

Figure 3: The probability tree of the combined insurance product $(j=1,2,3)$ and short-term rate processes between $t$ and $t+1$ given $K(x) \geq t$ and $r(0), r(1), \ldots, r(t)$.

possible dependence structures between interest rates and insurance products. It is important to point out that these probabilities are age-dependent and include an adjustment for the mortality risk since we use the information from the insurance market.

The martingale measures $Q_{x}^{(j)}, j=1,2,3$, are defined such that $W^{(j)}(x, t, n) / B(t)$ and $L(t, T) / B(t)$ are martingales. As mentioned in Section 2, we assume that the time- 0 premiums $V^{(j)}(x, 0, n), j=1,2,3$, of the term life insurance, pure endowment insurance, and endowment insurance are given exogenously. The annual short-term rate process $r(t)$ is governed by the BDT model with $q(t, l)=0.5$ and volatilities $\sigma_{r}(t)$ are given exogenously for $l=0,1, \ldots, t$ and $t=1,2, \ldots$. The conditional martingale probability of each possible outcome is defined by

$$
\begin{gathered}
b_{x}^{(j)}\left(t, 0, \mathbf{1}_{t}\right)=Q_{x}^{(j)}\left[K(x)>t, r(t+1)=r\left(t+1, l_{t}\right) \mid K(x) \geq t, \mathbf{1}_{t}\right], \\
b_{x}^{(j)}\left(t, 1, \mathbf{1}_{t}\right)=Q_{x}^{(j)}\left[K(x)>t, r(t+1)=r\left(t+1, l_{t}+1\right) \mid K(x) \geq t, \mathbf{1}_{t}\right], \\
b_{x}^{(j)}\left(t, 2, \mathbf{1}_{t}\right)=Q_{x}^{(j)}\left[K(x)=t, r(t+1)=r\left(t+1, l_{t}\right) \mid K(x) \geq t, \mathbf{1}_{t}\right], \\
b_{x}^{(j)}\left(t, 3, \mathbf{1}_{t}\right)=Q_{x}^{(j)}\left[K(x)=t, r(t+1)=r\left(t+1, l_{t}+1\right) \mid K(x) \geq t, \mathbf{1}_{t}\right],
\end{gathered}
$$

for $j=1,2,3$. These martingale probabilities are presented above each branch in Figure 3.

The main objective of this section is to determine $b_{x}^{(j)}$ s that will be used to evaluate equity-indexed annuities in later sections. 
To ensure that the discounted value process $L(t, T) / B(t)$ is a martingale, we must have

$$
b_{x}^{(j)}\left(t, 0, \mathbf{1}_{t}\right)+b_{x}^{(j)}\left(t, 2, \mathbf{1}_{t}\right)=\frac{1}{2}, \quad b_{x}^{(j)}\left(t, 1, \mathbf{1}_{t}\right)+b_{x}^{(j)}\left(t, 3, \mathbf{1}_{t}\right)=\frac{1}{2}
$$

for $j=1,2,3, t=0,1, \ldots$, and all $\mathbf{l}_{t}$. Note that the martingale mortality and survival probabilities are given, respectively, by

$$
\begin{aligned}
& q_{x}^{(j)}\left(t, \mathbf{l}_{t}\right)=Q_{x}^{(j)}\left[K(x)=t \mid K(x) \geq t, \mathbf{1}_{t}\right]=b_{x}^{(j)}\left(t, 2, \mathbf{l}_{t}\right)+b_{x}^{(j)}\left(t, 3, \mathbf{l}_{t}\right), \\
& p_{x}^{(j)}\left(t, \mathbf{l}_{t}\right)=Q_{x}^{(j)}\left[K(x)>t \mid K(x) \geq t, \mathbf{1}_{t}\right]=b_{x}^{(j)}\left(t, 0, \mathbf{1}_{t}\right)+b_{x}^{(j)}\left(t, 1, \mathbf{1}_{t}\right) .
\end{aligned}
$$

As in the short-term rate model, additional structure is needed to set the time- $t$ premiums. Similar to Black et al. [18], we suppose that the volatilities of insurance liabilities $\sigma_{x}^{(j)}\left(t, l_{t-1}\right)$ are defined at time $t$ by

$$
\begin{gathered}
\sigma_{x}^{(1)}\left(t, \mathbf{1}_{t-1}\right)^{2}=\operatorname{Var}_{x}^{(1)}\left[\ln \left(W^{(1)}\left(x, t, n, \mathbf{1}_{t-1}\right)\right) \mid K(x) \geq t, \mathbf{1}_{t-1}\right], \\
\sigma_{x}^{(j)}\left(t, \mathbf{1}_{t-1}\right)^{2}=\operatorname{Var}_{x}^{(j)}\left[\ln \left(1-W^{(j)}\left(x, t, n, \mathbf{1}_{t-1}\right)\right) \mid K(x) \geq t, \mathbf{1}_{t-1}\right],
\end{gathered}
$$

for $j=2,3, t=1,2, \ldots$, and all $\mathbf{l}_{t-1}$. Here, $\operatorname{Var}_{x}^{(j)}[\cdot]$ represents the conditional variance with respect to $Q_{x}^{(j)}$. We assume that the volatilities are deterministic but vary over time and are given exogenously. Gaillardetz [15] uses the natural logarithm function to ensure that each process remains strictly positive. Since $W^{(1)}$ is close to 0 , it directly uses $\ln \left(W^{(1)}\right)$ to ensure that the process remains strictly greater than 0 . On the other hand, it uses $\ln \left(1-W^{(j)}\right)$ for $j=2,3$ to ensure that the processes are strictly smaller than 1 since $W^{(j)}$ 's are closer to 1 .

In order to identify the martingale probabilities $b_{x}^{(j)}$, Gaillardetz [15] assumes the independence or the conditional independence between the interest rate process and the insurer's life. Here, the additional structure is provided by the choice of copulas. Indeed, the dependence structure between the interest rates and the premiums of insurance products is modeled using a copula. The main advantage of using copulas is that they separate a joint distribution function in two parts: the dependence structure and the marginal distribution functions. We use them because of their mathematical tractability and, based on the Sklar's Theorem, they can express all multivariate distributions. A comprehensive introduction may be found in Joe [21] or Nelsen [22]. Frees and Valdez [23], Wang [24], and Venter [25] have given an overview of copulas and their applications to actuarial science. Cherubini et al. [26] present the applications of copulas in finance. 
There exists a wide range of copulas that may define a joint cumulative distribution function. The simplest one is the independent copula

$$
C^{I}\left(F_{Y_{1}}\left(y_{1}\right), F_{Y_{2}}\left(y_{2}\right)\right)=F_{Y_{1}}\left(y_{1}\right) F_{Y_{2}}\left(y_{2}\right)
$$

where $F_{Y_{1}}$ and $F_{Y_{2}}$ are marginal cumulative distribution functions. Extreme copulas are defined using the upper and lower Frechet-Hoeffding bounds, which are given by

$$
\begin{gathered}
C^{U}\left(F_{Y_{1}}\left(y_{1}\right), F_{Y_{2}}\left(y_{2}\right)\right)=\min \left[F_{Y_{1}}\left(y_{1}\right), F_{Y_{2}}\left(y_{2}\right)\right], \\
C^{D}\left(F_{Y_{1}}\left(y_{1}\right), F_{Y_{2}}\left(y_{2}\right)\right)=\max \left[F_{Y_{1}}\left(y_{1}\right)+F_{Y_{2}}\left(y_{2}\right)-1,0\right] .
\end{gathered}
$$

One of the most important families of copulas is the archimedean copulas. Among them, the Cook-Johnson (Clayton) copula is widely used in actuarial science because of its desirable properties and simplicity. The Cook-Johnson copula with parameter $\kappa>0$ is given by

$$
C_{\kappa}^{C J}\left(F_{Y_{1}}\left(y_{1}\right), F_{Y_{2}}\left(y_{2}\right)\right)=\left[F_{Y_{1}}\left(y_{1}\right)^{-\kappa}+F_{Y_{2}}\left(y_{2}\right)^{-\kappa}-1\right]^{-1 / \kappa} \text {. }
$$

The Gaussian $(-1 \leq \kappa \leq 1)$ copula, which is often used in finance, is defined as

$$
C_{\kappa}^{G}\left(F_{Y_{1}}\left(y_{1}\right), F_{Y_{2}}\left(y_{2}\right)\right)=\Phi_{\kappa}\left(\Phi^{-1}\left(F_{Y_{1}}\left(y_{1}\right)\right), \Phi^{-1}\left(F_{Y_{2}}\left(y_{2}\right)\right)\right)
$$

where $\Phi_{\kappa}$ is the bivariate standard normal cumulative distribution function with correlation coefficient $\kappa$ and $\Phi^{-1}$ is the inverse of the standard normal cumulative distribution function. Hence, the parameter $\kappa$ in formulas (3.9) and (3.10) indicates the level of dependence between the insurance products and interest rates. is,

The joint cumulative distribution of $W^{(j)}$ and $r(t)$ is obtained using a copula $C_{\kappa(t)}$, that

$$
\begin{aligned}
Q_{x}^{(j)} & {\left[W^{(j)}\left(x, t+1, n, \mathbf{1}_{t}\right) \leq y_{1}, r(t+1) \leq y_{2} \mid K(x) \geq t, \mathbf{1}_{t}\right] } \\
& =C_{\kappa(t)}\left(Q_{x}^{(j)}\left[W^{(j)}\left(x, t+1, n, \mathbf{1}_{t}\right) \leq y_{1} \mid K(x) \geq t, \mathbf{1}_{t}\right], Q\left[r(t+1) \leq y_{2} \mid \mathbf{1}_{t}\right]\right),
\end{aligned}
$$

for $j=1,2,3$, where the copula may be defined by either (3.6), (3.7), (3.8), (3.9), or (3.10).

The martingale probabilities have the following constraints:

$$
\begin{aligned}
b_{x}^{(j)}\left(t, 2, \mathbf{l}_{t}\right) \\
=Q_{x}^{(j)}\left[W^{(j)}\left(x, t+1, n, \mathbf{l}_{t}\right)=1, r(t+1)=r\left(t+1, l_{t}\right) \mid K(x) \geq t, \mathbf{l}_{t}\right] \\
=Q_{x}^{(j)}\left[W^{(j)}\left(x, t+1, n, \mathbf{l}_{t}\right) \leq 1, r(t+1) \leq r\left(t+1, l_{t}\right) \mid K(x) \geq t, \mathbf{l}_{t}\right] \\
\\
\quad-Q_{x}^{(j)}\left[W^{(j)}\left(x, t+1, n, \mathbf{l}_{t}\right) \leq V^{(j)}\left(x, t+1, n,\left\{\mathbf{l}_{t}, l_{t}\right\}\right), r(t+1) \leq r\left(t+1, l_{t}\right) \mid K(x) \geq t, \mathbf{l}_{t}\right] .
\end{aligned}
$$


Journal of Probability and Statistics

It follows from (3.11) that

$$
\begin{gathered}
b_{x}^{(j)}\left(t, 2, \mathbf{1}_{t}\right) \\
=Q_{x}^{(j)}\left[r(t+1) \leq r\left(t+1, l_{t}\right) \mid K(x) \geq t, \mathbf{1}_{t}\right] \\
-C_{\kappa(t)}\left(Q_{x}^{(j)}\left[W^{(j)}\left(x, t+1, n, \mathbf{1}_{t}\right) \leq V^{(j)}\left(x, t+1, n,\left\{\mathbf{1}_{t}, l_{t}\right\}\right) \mid K(x) \geq t, \mathbf{1}_{t}\right],\right. \\
\left.Q\left[r(t+1) \leq r\left(t+1, l_{t}\right) \mid \mathbf{1}_{t}\right]\right) .
\end{gathered}
$$

Using the following inequality

$$
V^{(j)}\left(x, t+1, n,\left\{\mathbf{1}_{t}, l_{t}\right\}\right) \geq V^{(j)}\left(x, t+1, n,\left\{\mathbf{1}_{t}, l_{t}+1\right\}\right)
$$

in (3.13) leads to

$$
\begin{aligned}
b_{x}^{(j)}\left(t, 2, \mathbf{1}_{t}\right) & =0.5-C_{\kappa(t)}\left(b_{x}^{(j)}\left(t, 0, \mathbf{1}_{t}\right)+b_{x}^{(j)}\left(t, 1, \mathbf{1}_{t}\right), 0.5\right) \\
& =0.5-C_{\kappa(t)}\left(p_{x}^{(j)}\left(t, \mathbf{1}_{t}\right), 0.5\right)
\end{aligned}
$$

for $j=1,3$, and we have for $j=2$

$$
\begin{aligned}
b_{x}^{(2)}\left(t, 2, \mathbf{l}_{t}\right) & =Q_{x}^{(2)}\left[W^{(2)}\left(x, t+1, n, \mathbf{l}_{t}\right)=0, r(t+1)=r\left(t+1, l_{t}\right) \mid K(x) \geq t, \mathbf{l}_{t}\right] \\
& =Q_{x}^{(2)}\left[W^{(2)}\left(x, t+1, n, \mathbf{l}_{t}\right) \leq 0, r(t+1) \leq r\left(t+1, l_{t}\right) \mid K(x) \geq t, \mathbf{l}_{t}\right] .
\end{aligned}
$$

It follows from (3.11) that

$$
\begin{aligned}
b_{x}^{(2)}\left(t, 2, \mathbf{1}_{t}\right) & =C_{\kappa(t)}\left(Q_{x}^{(2)}\left[W^{(2)}\left(x, t+1, n, \mathbf{1}_{t}\right) \leq 0 \mid K(x) \geq t, \mathbf{1}_{t}\right], Q\left[r(t+1) \leq r\left(t+1, l_{t}\right) \mid\right.\right. \\
& =C_{\kappa(t)}\left(q_{x}^{(2)}\left(t, \mathbf{1}_{t}\right), 0.5\right) .
\end{aligned}
$$




\subsection{Term Life Insurance}

Proposition 3.1. For given $V^{(1)}\left(x, 0, n, l_{0}\right) \quad(n=1,2, \ldots, \tau)$, copulas $C_{\kappa(t)}$, and volatilities $\sigma_{x}^{(1)}\left(t, \mathbf{1}_{t-1}\right)\left(t=1,2, \ldots, \tau\right.$ and all $\left.\mathbf{1}_{t-1}\right)$, the age-dependent, mortality risk-adjusted martingale probabilities are given by

$$
\begin{gathered}
b_{x}^{(1)}\left(t, 2, \mathbf{1}_{t}\right)=0.5-C_{\kappa(t)}\left(1-V^{(1)}\left(x, t, t+1, \mathbf{l}_{t}\right)\left(1+r\left(t, l_{t}\right)\right), 0.5\right), \\
b_{x}^{(1)}\left(t, 3, \mathbf{l}_{t}\right)=V^{(1)}\left(x, t, t+1, \mathbf{1}_{t}\right)\left(1+r\left(t, l_{t}\right)\right)-b_{x}^{(1)}\left(t, 2, \mathbf{l}_{t}\right), \\
b_{x}^{(1)}\left(t, i, \mathbf{l}_{t}\right)=\frac{1}{2}-b_{x}^{(1)}\left(t, i+2, \mathbf{1}_{t}\right),
\end{gathered}
$$

for $i=0,1$, where the price at time $t$ is defined recursively using

$$
\begin{aligned}
& V^{(1)}\left(x, t+1, n,\left\{\mathbf{1}_{t}, l_{t}\right\}\right) \\
& =\frac{V^{(1)}\left(x, t, n, \mathbf{l}_{t}\right)\left(1+r\left(t, l_{t}\right)\right)-b_{x}^{(1)}\left(t, 2, \mathbf{l}_{t}\right)-b_{x}^{(1)}\left(t, 3, \mathbf{l}_{t}\right)}{b_{x}^{(1)}\left(t, 0, \mathbf{l}_{t}\right)+b_{x}^{(1)}\left(t, 1, \mathbf{l}_{t}\right) e^{-\left(\left(b_{x}^{(1)}\left(t, 0, \mathbf{l}_{t}\right)+b_{x}^{(1)}\left(t, 1, \mathbf{l}_{t}\right)\right) /\left\{b_{x}^{(1)}\left(t, 0, \mathbf{l}_{t}\right) b_{x}^{(1)}\left(t, 1, \mathbf{l}_{t}\right)\right\}^{0.5}\right) \sigma_{x}^{(1)}\left(t+1, \mathbf{l}_{t}\right)}}, \\
& V^{(1)}\left(x, t+1, n,\left\{\mathbf{1}_{t}, l_{t}+1\right\}\right) \\
& =\frac{V^{(1)}\left(x, t, n, \mathbf{l}_{t}\right)\left(1+r\left(t, l_{t}\right)\right)-b_{x}^{(1)}\left(t, 2, \mathbf{l}_{t}\right)-b_{x}^{(1)}\left(t, 3, \mathbf{l}_{t}\right)}{b_{x}^{(1)}\left(t, 1, \mathbf{l}_{t}\right)+b_{x}^{(1)}\left(t, 0, \mathbf{l}_{t}\right) e^{\left(\left(b_{x}^{(1)}\left(t, 0, \mathbf{l}_{t}\right)+b_{x}^{(1)}\left(t, 1, \mathbf{l}_{t}\right)\right) /\left\{b_{x}^{(1)}\left(t, 0, \mathbf{l}_{t}\right) b_{x}^{(1)}\left(t, 1, \mathbf{l}_{t}\right)\right\}^{0.5}\right) \sigma_{x}^{(1)}\left(t+1, \mathbf{l}_{t}\right)}},
\end{aligned}
$$

for $t=0,2, \ldots, n-2$ and all $\mathbf{1}_{t}$.

Proof. The proof is similar to the proof of Proposition 3.1 of Gaillardetz [15] and can be found in Gaillardetz [27].

With the martingale structure identified, the $n$-year term life insurance premiums may be reproduced as the expected discounted payoff of the insurance

$$
V^{(1)}(x, 0, n)=E_{x}^{(1)}\left[\frac{1_{\{K(x)<n\}}}{B(K(x)+1)}\right]
$$

\subsection{Pure Endowment Insurance}

Proposition 3.2. For given $V^{(2)}\left(x, 0, n, l_{0}\right) \quad(n=1,2, \ldots, \tau)$, copulas $C_{\kappa(t)}$, and volatilities $\sigma_{x}^{(2)}\left(t, \mathbf{1}_{t-1}\right)\left(t=1,2, \ldots, \tau\right.$ and all $\left.\mathbf{1}_{t-1}\right)$, the age-dependent, mortality risk-adjusted martingale probabilities are given by

$$
\begin{aligned}
& b_{x}^{(2)}\left(t, 2, \mathbf{l}_{t}\right)=C_{\kappa(t)}\left(1-V^{(2)}\left(x, t, t+1, \mathbf{1}_{t}\right)\left(1+r\left(t, l_{t}\right)\right), 0.5\right), \\
& b_{x}^{(2)}\left(t, 3, \mathbf{1}_{t}\right)=1-V^{(2)}\left(x, t, t+1, \mathbf{1}_{t}\right)\left(1+r\left(t, l_{t}\right)\right)-b_{x}^{(2)}\left(t, 2, \mathbf{1}_{t}\right),
\end{aligned}
$$


Journal of Probability and Statistics

$$
b_{x}^{(2)}\left(t, i, \mathbf{l}_{t}\right)=\frac{1}{2}-b_{x}^{(2)}\left(t, i+2, \mathbf{l}_{t}\right)
$$

for $i=0,1$, where the price at time $t$ is defined recursively using

$$
\begin{aligned}
& V^{(2)}\left(x, t+1, n,\left\{\mathbf{l}_{t}, l_{t}\right\}\right) \\
& =\frac{V^{(2)}\left(x, t, n, \mathbf{l}_{t}\right)\left(1+r\left(t, l_{t}\right)\right)-b_{x}^{(2)}\left(t, 1, \mathbf{l}_{t}\right)\left(1-e^{\left(\left(b_{x}^{(2)}\left(t, 0, \mathbf{l}_{t}\right)+b_{x}^{(2)}\left(t, 1, \mathbf{l}_{t}\right)\right) /\left\{b_{x}^{(2)}\left(t, 0, \mathbf{l}_{t}\right) b_{x}^{(2)}\left(t, 1, \mathbf{l}_{t}\right)\right\}^{0.5}\right) \sigma_{x}^{(2)}\left(t+1, \mathbf{l}_{t}\right)}\right)}{b_{x}^{(2)}\left(t, 0, \mathbf{l}_{t}\right)+b_{x}^{(2)}\left(t, 1, \mathbf{l}_{t}\right) e^{\left(\left(b_{x}^{(2)}\left(t, 0, \mathbf{l}_{t}\right)+b_{x}^{(2)}\left(t, 1, \mathbf{l}_{t}\right)\right) /\left\{b_{x}^{(2)}\left(t, 0, \mathbf{l}_{t}\right) b_{x}^{(2)}\left(t, 1, \mathbf{l}_{t}\right)\right\}^{0.5}\right) \sigma_{x}^{(2)}\left(t+1, \mathbf{l}_{t}\right)}}, \\
& V^{(2)}\left(x, t+1, n,\left\{\mathbf{1}_{t}, l_{t}+1\right\}\right) \\
& =\frac{V^{(2)}\left(x, t, n, \mathbf{1}_{t}\right)\left(1+r\left(t, l_{t}\right)\right)-b_{x}^{(2)}\left(t, 0, \mathbf{1}_{t}\right)\left(1-e^{-\left(\left(b_{x}^{(2)}\left(t, 0, \mathbf{l}_{t}\right)+b_{x}^{(2)}\left(t, 1, \mathbf{l}_{t}\right)\right) /\left\{b_{x}^{(2)}\left(t, 0, \mathbf{l}_{t}\right) b_{x}^{(2)}\left(t, 1, \mathbf{l}_{t}\right)\right\}^{0.5}\right) \sigma_{x}^{(2)}\left(t+1, \mathbf{l}_{t}\right)}\right)}{b_{x}^{(2)}\left(t, 1, \mathbf{1}_{t}\right)+b_{x}^{(2)}\left(t, 0, \mathbf{l}_{t}\right) e^{-\left(\left(b_{x}^{(2)}\left(t, 0, \mathbf{l}_{t}\right)+b_{x}^{(2)}\left(t, 1, \mathbf{l}_{t}\right)\right) /\left\{b_{x}^{(2)}\left(t, 0, \mathbf{1}_{t}\right) b_{x}^{(2)}\left(t, 1, \mathbf{l}_{t}\right)\right\}^{0.5}\right) \sigma_{x}^{(2)}\left(t+1, \mathbf{l}_{t}\right)}},
\end{aligned}
$$

for $t=0,2, \ldots, n-2$ and all $\mathbf{1}_{t}$.

Proof. The proof is similar to the proof of Proposition 3.2 of Gaillardetz [15] and can be found in Gaillardetz [27].

With the martingale structure identified, the $n$-year pure endowment insurance premiums may be reproduced as the expected discounted payoff of the insurance

$$
V^{(2)}(x, 0, n)=E_{x}^{(2)}\left[\frac{1_{\{K(x) \geq n\}}}{B(n)}\right] .
$$

\subsection{Endowment Insurance}

There is no general solution for the endowment insurance products since the $n$-year endowment insurance price at time $n-2$ may not be expressed using only either mortality or survival probabilities. For the $n$-year term-life insurance, the time- $(n-1)$ price is determined based on the death martingale probabilities and the $n$-year pure endowment price may be obtained using the survival probabilities at time $n-1$. Therefore, once you combine both products to form an endowment insurance, there is no way to solve explicitly for the martingale probabilities. However, closed-from solutions may be derived for the independent, upper and lower copulas. Numerical methods need to be used for the Cook-Johnson and Gaussian copulas. Furthermore, the width of the participation rate bands for the unified approach is narrow under deterministic interest (see Gaillardetz and Lin [13]). For these reasons, we are focusing on the independent and Frechet-Hoeffding bounds. 
Proposition 3.3. For given $V^{(3)}\left(x, 0, n, l_{0}\right)(n=1,2, \ldots, \tau)$, copulas $C$, and volatilities $\sigma_{x}^{(3)}\left(t, \mathbf{1}_{t-1}\right)$ $\left(t=1,2, \ldots, \tau\right.$ and all $\left.\mathbf{1}_{t-1}\right)$, the age-dependent, mortality risk-adjusted martingale probabilities are given by

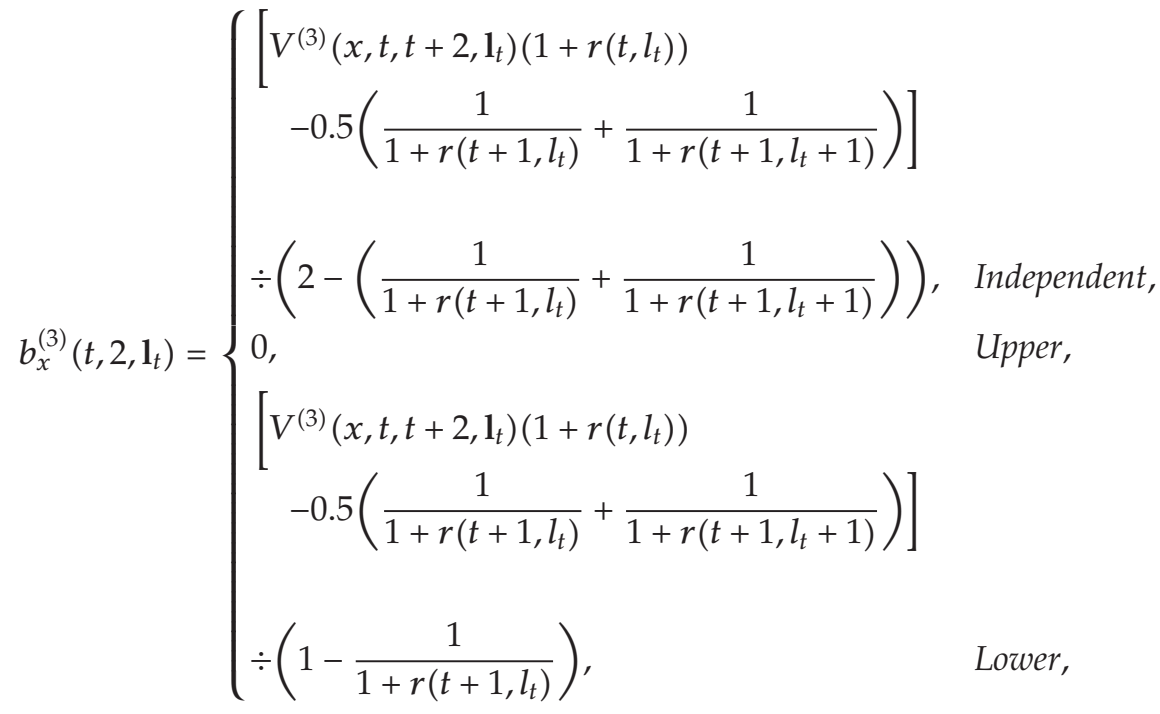

$$
\begin{aligned}
& b_{x}^{(3)}\left(t, 3, \mathbf{1}_{t}\right)= \begin{cases}b_{x}^{(3)}\left(t, 2, \mathbf{1}_{t}\right), & \text { Independent, } \\
& \left.-0.5\left(\frac{1}{1+r\left(t+1, l_{t}\right)}+\frac{1}{1+r\left(t+1, l_{t}+1\right)}\right)\right] \\
& \\
\hdashline\left(1-\frac{1}{1+r\left(t+1, l_{t}+1\right)}\right), & \text { Upper, } \\
0, & \text { Lower, }\end{cases} \\
& b_{x}^{(3)}\left(t, i, \mathbf{l}_{t}\right)=0.5-b_{x}^{(3)}\left(t, i+2, \mathbf{l}_{t}\right) \text {, }
\end{aligned}
$$

for $i=0,1$, where the price at time $t$ is defined recursively using

$$
\begin{aligned}
V^{(3)}\left(x, t+1, n,\left\{\mathbf{1}_{t}, l_{t}\right\}\right) \\
=\left[V^{(3)}\left(x, t, n, \mathbf{1}_{t}\right)\left(1+r\left(t, l_{t}\right)\right)-b_{x}^{(3)}\left(t, 2, \mathbf{1}_{t}\right)-b_{x}^{(3)}\left(t, 3, \mathbf{1}_{t}\right)\right. \\
\left.\quad-b_{x}^{(3)}\left(t, 1, \mathbf{1}_{t}\right)\left(1-e^{\left(\left(b_{x}^{(3)}\left(t, 0, \mathbf{l}_{t}\right)+b_{x}^{(3)}\left(t, 1,1, \mathbf{l}_{t}\right)\right) /\left\{b_{x}^{(3)}\left(t, 0, \mathbf{l}_{t}\right) b_{x}^{(3)}\left(t, 1, \mathbf{l}_{t}\right)\right\}^{0.5}\right) \sigma_{x}^{(3)}\left(t+1, \mathbf{l}_{t}\right)}\right)\right]
\end{aligned}
$$




$$
\begin{aligned}
& \div\left(b_{x}^{(3)}\left(t, 0, \mathbf{1}_{t}\right)+b_{x}^{(3)}\left(t, 1, \mathbf{1}_{t}\right) e^{\left(\left(b_{x}^{(3)}\left(t, 0, \mathbf{l}_{t}\right)+b_{x}^{(3)}\left(t, 1, \mathbf{l}_{t}\right)\right) /\left\{b_{x}^{(3)}\left(t, 0, \mathbf{l}_{t}\right) b_{x}^{(3)}\left(t, 1, \mathbf{l}_{t}\right)\right\}^{0.5}\right) \sigma_{x}^{(3)}\left(t+1, \mathbf{l}_{t}\right)}\right), \\
& V^{(3)}\left(x, t+1, n,\left\{\mathbf{l}_{t}, l_{t}\right\}\right) \\
& =\left[V^{(3)}\left(x, t, n, \mathbf{l}_{t}\right)\left(1+r\left(t, l_{t}\right)\right)-b_{x}^{(3)}\left(t, 2, \mathbf{1}_{t}\right)-b_{x}^{(3)}\left(t, 3, \mathbf{1}_{t}\right)\right. \\
& \left.-b_{x}^{(3)}\left(t, 0, \mathbf{l}_{t}\right)\left(1-e^{-\left(\left(b_{x}^{(3)}\left(t, 0, \mathbf{l}_{t}\right)+b_{x}^{(3)}\left(t, 1, \mathbf{l}_{t}\right)\right) /\left\{b_{x}^{(3)}\left(t, 0,0, \mathbf{l}_{t}\right) b_{x}^{(3)}\left(t, 1, \mathbf{l}_{t}\right)\right\}^{0.5}\right) \sigma_{x}^{(3)}\left(t+1, \mathbf{l}_{t}\right)}\right)\right] \\
& \div\left(b_{x}^{(3)}\left(t, 1, \mathbf{1}_{t}\right)+b_{x}^{(3)}\left(t, 0, \mathbf{1}_{t}\right) e^{-\left(\left(b_{x}^{(3)}\left(t, 0, \mathbf{l}_{t}\right)+b_{x}^{(3)}\left(t, 1, \mathbf{l}_{t}\right)\right) /\left\{b_{x}^{(3)}\left(t, 0, \mathbf{l}_{t}\right) b_{x}^{(3)}\left(t, 1, \mathbf{l}_{t}\right)\right\}^{0.5}\right) \sigma_{x}^{(3)}\left(t+1, \mathbf{l}_{t}\right)}\right),
\end{aligned}
$$

for $t=0,2, \ldots, n-3$ and all $\mathbf{1}_{t}$.

Proof. The proof can be found in Gaillardetz [27].

Since we suppose that the time- 0 insurance prices, the insurance volatilities, the zerocoupon bond prices, and the interest rate volatility are given exogenously, it is possible to extract the stochastic structure of each insurance products using Propositions 3.1, 3.2, and 3.3. There are constraints on the parameters because the martingale probabilities should be strictly positive. However, there is no closed-form solution for the stochastic interest models.

Theoretically, there exists a natural hedging between the insurance and annuity products. However, Gaillardetz and Lin [13] argue that it is reasonable to evaluate insurances and annuities separatelysince in practice due to certain regulatory and accounting constraints and issues such as moral hazard and anti-selection.

\subsection{Determination of Insurance Volatility Structure}

For implementation purposes, we now relax the assumption of exogenous insurance volatilities. In Subsections 3.1, 3.2, and 3.3, the volatilities of insurance liabilities $\sigma_{x}^{(j)}\left(t, l_{t-1}\right)$ defined by either (3.4) or (3.5) were supposed to be known. However, identifying these volatilities is extremely challenging due to the lack of empirical data and studies. Similar to Gaillardetz [15], we extract an implied volatility from the insurance market under certain assumptions.

There are three different sources that define the insurance volatilities: the interest rates, the insurance prices, and the martingale probabilities. The implied insurance volatilities is obtained assuming that the short-term rate has no impact on the martingale probabilities. Thus, we extract the insurance volatility such that the martingale probabilities in the case of an up move from the interest rate process are equal to the martingale probabilities in the case of a down move. Let $\sigma_{x}^{(j)^{\prime}}\left(t, \mathbf{1}_{t-1}\right)\left(j=1,2,3, t=1,2, \ldots\right.$, and all $\left.\mathbf{1}_{t-1}\right)$ denote the implied volatilities defined by (3.4) for $j=1$ and (3.5) for $j=2,3$, under the following constraint:

$$
q_{x}^{(j)}\left(t+1,\left\{\mathbf{1}_{t}, l_{t}\right\}\right)=q_{x}^{(j)}\left(t+1,\left\{\mathbf{1}_{t}, l_{t}+1\right\}\right)
$$


for $j=1,2,3$. In other words, insurance companies that do not react to the interest rate change should have an insurance volatility close to $\sigma_{x}^{(j)^{\prime}}$. Gaillardetz $[13,27]$ explain that behavior of insurance companies facing the interest rate shifts could be understood through these volatilities. They also describe recursive formulas to obtain numerically the implied volatilities. In the following examples, equity-indexed annuity contracts are evaluated using the implied volatilities, which are obtained from (3.33).

\section{Martingale Measures for Equity-Linked Products}

Due to their unique designs, equity-linked products involve mortality and financial risks since these type of contracts provide both death and accumulation/survival benefits. Moreover, the level of these benefits are linked to the financial market performance and an equity index in particular. Hence, it is natural to assume that equity-linked products belong to a combined insurance and financial markets since they are simultaneously subject to the interest rate, equity, and mortality risks. Similar to Section 3, we evaluate these types of products by evaluating the death benefits and survival benefits separately. Under this approach, two martingale measures again need to be generated: one for death benefits and another for survival benefits. Furthermore, these martingale measures should be such that they reproduce the index values in Section 2 and the premiums of insurance products under stochastic interest rates in Section 3. In other words, the marginal probabilities derived in the previous sections should be preserved, and the martingale measures $Q_{x}^{(j)+}, j=1,2,3$ are such that $\left\{W^{(j)}(x, t, n) / B(t), t=0,1, \ldots\right\},\{L(t, T) / B(t), t=0,1, \ldots, T$ and $T=1, \ldots\}$, and $\{S(k) / B(k), k=0, \Delta, \ldots\}$ will remain martingales. Let $e_{x}^{(j)}\left(t, i, \mathbf{i}_{t}, \mathbf{l}_{t}\right)$ denote the martingale probability under $Q_{x}^{(j)+}$ such that $(x)$ survives and

$$
\left\{\begin{array}{l}
r(t+1)=r\left(t+1, l_{t}\right), \quad \frac{S(t+1)}{S(t)}=\gamma(t+1, i), \quad i=0, \ldots, N \\
r(t+1)=r\left(t+1, l_{t}+1\right), \quad \frac{S(t+1)}{S(t)}=\gamma(t+1, i-(N+1)), \quad i=N+1, \ldots, 2 N+1
\end{array}\right.
$$

or the martingale probability such that $(x)$ dies and

$$
\left\{\begin{array}{l}
r(t+1)=r\left(t+1, l_{t}\right), \quad \frac{S(t+1)}{S(t)}=r(t, i-(2 N+2)), \quad i=2 N+2, \ldots, 3 N+2, \\
r(t+1)=r\left(t+1, l_{t}+1\right), \quad \frac{S(t+1)}{S(t)}=r(t, i-(3 N+3)), \quad i=3 N+3, \ldots, 4 N+3,
\end{array}\right.
$$

between $t$ and $t+1$ given $S(t), K(x) \geq t$, and $\mathbf{l}_{t}$ as illustrated in Figure 4. The function $\gamma$ is given explicitly by (2.12).

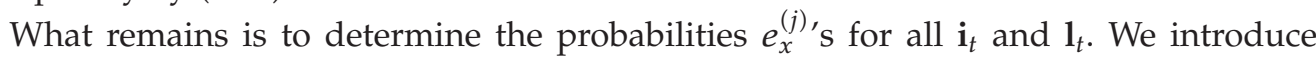
the dependency between the index process, the short-term rate, and the premiums of 
insurance products using copulas. Let $G_{x}^{(j)}, j=1,2,3$, denote this joint conditional cumulative distribution function over time $t$ and $t+1$. That is

$$
\begin{gathered}
G_{x}^{(j)}\left(y_{1}, y_{2}, y_{3} ; \mathbf{i}_{t}, \mathbf{l}_{t}\right)=Q_{x}^{(j)+}\left[S(t+1) \leq y_{1}, W^{(j)}\left(x, t+1, n, \mathbf{1}_{t}\right) \leq y_{2},\right. \\
\left.r(t+1) \leq y_{3} \mid K(x) \geq t, \mathbf{i}_{t}, \mathbf{1}_{t}\right] .
\end{gathered}
$$

As explained, the marginal cumulative distribution functions of the insurance products and the index are preserved under the extended measures, that is,

$$
\begin{aligned}
& G_{x}^{(j)}\left(\infty, y_{2}, y_{3} ; \mathbf{i}_{t}, \mathbf{l}_{t}\right) \\
& \quad=Q_{x}^{(j)}\left[W^{(j)}\left(x, t+1, n, \mathbf{l}_{t}\right) \leq y_{2}, r(t+1) \leq y_{3} \mid \mathbf{i}_{t}, \mathbf{l}_{t}\right], \\
& G_{x}^{(j)}\left(y_{1}, \infty, \infty ; \mathbf{i}_{t}, \mathbf{l}_{t}\right)=Q\left[S(t+1) \leq y_{1} \mid \mathbf{i}_{t}, \mathbf{l}_{t}\right],
\end{aligned}
$$

which are determined using (3.18), (3.19), and (3.20) for $j=1,(3.24),(45)$, and (3.26) for $j=2,(3.29)$, (3.30), as well as (3.31) for $j=3$, and (2.13) for the index. Let $C_{\kappa(t)}$ be the choice of copula, then the cumulative distribution function $G_{x}^{(j)}$ is defined by

$$
G_{x}^{(j)}\left(y_{1}, y_{2}, y_{3} ; \mathbf{i}_{t}, \mathbf{l}_{t}\right)=C_{\kappa(t)}\left(G_{x}^{(j)}\left(y_{1}, \infty, \infty ; \mathbf{i}_{t}, \mathbf{l}_{t}\right), G_{x}^{(j)}\left(\infty, y_{2}, y_{3} ; \mathbf{i}_{t}, \mathbf{l}_{t}\right)\right),
$$

where $\kappa(t)$ represents the free parameter between $t$ and $t+1$ that indicate the level of dependence between the insurance product, interest rate, and the index processes. Here, the copula $C_{\kappa(t)}$ could be defined using either (3.6), (3.7), (3.8), (3.9), or (3.10). Note that in some cases, for example, the lower copula (3.8), the function $G_{x}^{(j)}$ would not be a cumulative distribution function. We also remark that $G_{x}^{(j)}$ 's are functions of $K(x) \geq t$, but for notational simplicity we suppress $K(x)$.

The martingale probabilities can be obtained from the cumulative distribution function and are given by

$$
\begin{aligned}
e_{x}^{(j)}\left(t, i, \mathbf{i}_{t}, \mathbf{l}_{t}\right)= & G_{x}^{(j)}\left(S(t) \gamma(t+1, i), V^{(j)}\left(x, t+1, n,\left\{\mathbf{1}_{t}, l_{t}\right\}\right), r\left(t+1, l_{t}\right) ; \mathbf{i}_{t}, \mathbf{l}_{t}\right) \\
& -G_{x}^{(j)}\left(S(t) \gamma(t+1, i-1), V^{(j)}\left(x, t+1, n,\left\{\mathbf{1}_{t}, l_{t}\right\}\right), r\left(t+1, l_{t}\right) ; \mathbf{i}_{t}, \mathbf{1}_{t}\right),
\end{aligned}
$$

for $i=0, \ldots, N$,

$$
\begin{aligned}
e_{x}^{(j)}\left(t, i, \mathbf{i}_{t}, \mathbf{l}_{t}\right)= & G_{x}^{(j)}\left(S(t) \gamma(t+1, i-N-1), V^{(j)}\left(x, t+1, n,\left\{\mathbf{1}_{t}, l_{t}+1\right\}\right), r\left(t+1, l_{t}+1\right) ; \mathbf{i}_{t}, \mathbf{l}_{t}\right) \\
& -G_{x}^{(j)}\left(S(t) \gamma(t+1, i-N-2), V^{(j)}\left(x, t+1, n,\left\{\mathbf{1}_{t}, l_{t}+1\right\}\right), r\left(t+1, l_{t}+1\right) ; \mathbf{i}_{t}, \mathbf{l}_{t}\right),
\end{aligned}
$$




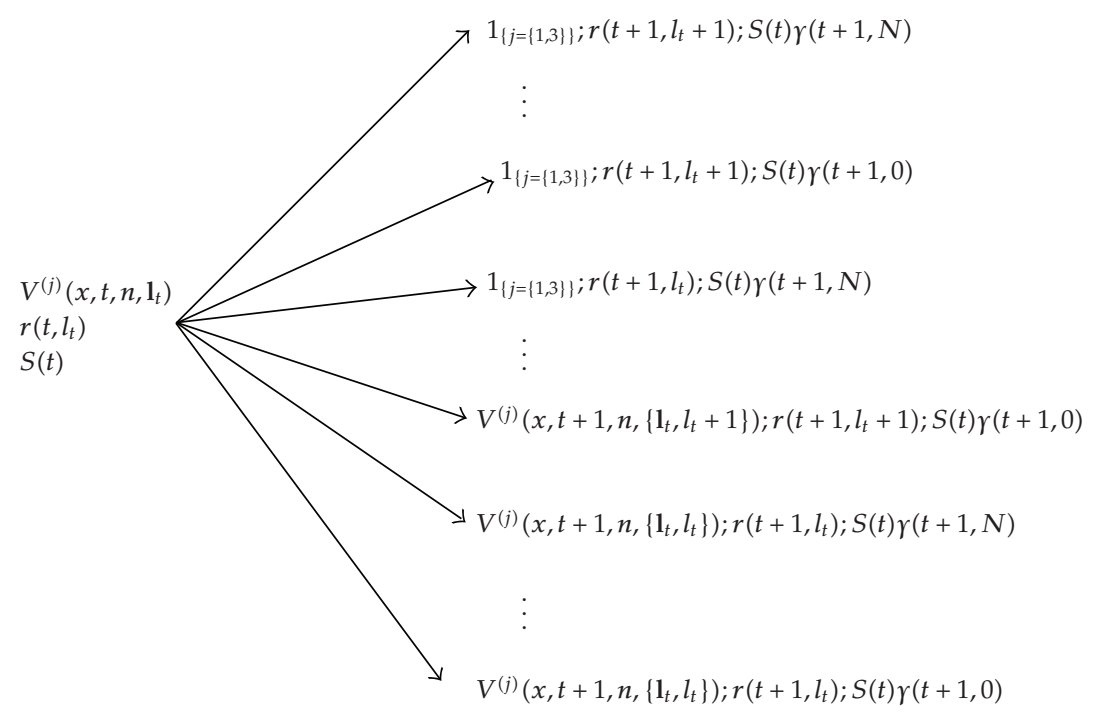

Figure 4: The probability tree of the combined insurance product $(j=1,2,3)$, short-term rate, and index processes between $t$ and $t+1$ given that $K(x) \geq t, \mathbf{1}_{t}$, and $\mathbf{i}_{t}$.

for $i=N+1, \ldots, 2 N+1$,

$$
\begin{aligned}
e_{x}^{(j)}\left(t, i, \mathbf{i}_{t}, \mathbf{l}_{t}\right)= & G_{x}^{(j)}\left(S(t) \gamma(t+1, i-2 N-2), 1, r\left(t+1, l_{t}\right) ; \mathbf{i}_{t}, \mathbf{1}_{t}\right) \\
& -G_{x}^{(j)}\left(S(t) \gamma(t+1, i-2 N-3), 1, r\left(t+1, l_{t}\right) ; \mathbf{i}_{t}, \mathbf{l}_{t}\right) \\
& -G_{x}^{(j)}\left(S(t) \gamma(t+1, i-2 N-2), V^{(j)}\left(x, t+1, n,\left\{\mathbf{1}_{t}, l_{t}\right\}\right), r\left(t+1, l_{t}\right) ; \mathbf{i}_{t}, \mathbf{l}_{t}\right) \\
& +G_{x}^{(j)}\left(S(t) \gamma(t+1, i-2 N-3), V^{(j)}\left(x, t+1, n,\left\{\mathbf{1}_{t}, l_{t}\right\}\right), r\left(t+1, l_{t}\right) ; \mathbf{i}_{t}, \mathbf{l}_{t}\right),
\end{aligned}
$$

for $i=2 N+2, \ldots, 3 N+2$, and

$$
\begin{aligned}
e_{x}^{(j)}\left(t, i, \mathbf{i}_{t}, \mathbf{l}_{t}\right)= & G_{x}^{(j)}\left(S(t) \gamma(t+1, i-3 N-3), 1, r\left(t+1, l_{t}+1\right) ; \mathbf{i}_{t}, \mathbf{l}_{t}\right) \\
& -G_{x}^{(j)}\left(S(t) \gamma(t+1, i-3 N-4), 1, r\left(t+1, l_{t}+1\right) ; \mathbf{i}_{t}, \mathbf{l}_{t}\right) \\
& -G_{x}^{(j)}\left(S(t) \gamma(t+1, i-3 N-3), V^{(j)}\left(x, t+1, n,\left\{\mathbf{l}_{t}, l_{t}\right\}\right), r\left(t+1, l_{t}+1\right) ; \mathbf{i}_{t}, \mathbf{l}_{t}\right) \\
& -G_{x}^{(j)}\left(S(t) \gamma(t+1, i-3 N-3), 1, r\left(t+1, l_{t}\right) ; \mathbf{i}_{t}, \mathbf{l}_{t}\right) \\
& +G_{x}^{(j)}\left(S(t) \gamma(t+1, i-3 N-4), V^{(j)}\left(x, t+1, n,\left\{\mathbf{1}_{t}, l_{t}\right\}\right), r\left(t+1, l_{t}+1\right) ; \mathbf{i}_{t}, \mathbf{l}_{t}\right)
\end{aligned}
$$


Journal of Probability and Statistics

$$
\begin{aligned}
& +G_{x}^{(j)}\left(S(t) \gamma(t+1, i-3 N-4), 1, r\left(t+1, l_{t}\right) ; \mathbf{i}_{t}, \mathbf{l}_{t}\right) \\
& +G_{x}^{(j)}\left(S(t) \gamma(t+1, i-3 N-3), V^{(j)}\left(x, t+1, n,\left\{\mathbf{1}_{t}, l_{t}\right\}\right), r\left(t+1, l_{t}\right) ; \mathbf{i}_{t}, \mathbf{1}_{t}\right) \\
& -G_{x}^{(j)}\left(S(t) \gamma(t+1, i-3 N-4), V^{(j)}\left(x, t+1, n,\left\{\mathbf{1}_{t}, l_{t}\right\}\right), r\left(t+1, l_{t}\right) ; \mathbf{i}_{t}, \mathbf{1}_{t}\right),
\end{aligned}
$$

for $i=3 N+3, \ldots, 4 N+3$ and $j=1,3$, where $G_{x}^{(j)}\left(S(t) \gamma(t+1,-1), \ldots ; \mathbf{i}_{t}, \mathbf{1}_{t}\right)=0$ and $G_{x}^{(j)}\left(\ldots ; \mathbf{i}_{t}, \mathbf{l}_{t}\right)$ is obtained using (4.5). Similarly, for $j=2$,

$$
\begin{aligned}
e_{x}^{(2)}\left(t, i, \mathbf{i}_{t}, \mathbf{l}_{t}\right)= & G_{x}^{(2)}\left(S(t) \gamma(t+1, i), V^{(2)}\left(x, t+1, n,\left\{\mathbf{1}_{t}, l_{t}\right\}\right), r\left(t+1, l_{t}\right) ; \mathbf{i}_{t}, \mathbf{l}_{t}\right) \\
& -G_{x}^{(2)}\left(S(t) \gamma(t+1, i-1), V^{(2)}\left(x, t+1, n,\left\{\mathbf{1}_{t}, l_{t}\right\}\right), r\left(t+1, l_{t}\right) ; \mathbf{i}_{t}, \mathbf{l}_{t}\right) \\
& -G_{x}^{(2)}\left(S(t) \gamma(t+1, i), V^{(2)}\left(x, t+1, n,\left\{\mathbf{1}_{t}, l_{t}+1\right\}\right), r\left(t+1, l_{t}\right) ; \mathbf{i}_{t}, \mathbf{l}_{t}\right) \\
& +G_{x}^{(2)}\left(S(t) \gamma(t+1, i-1), V^{(2)}\left(x, t+1, n,\left\{\mathbf{1}_{t}, l_{t}+1\right\}\right), r\left(t+1, l_{t}\right) ; \mathbf{i}_{t}, \mathbf{l}_{t}\right),
\end{aligned}
$$

for $i=0, \ldots, N$,

$$
\begin{aligned}
e_{x}^{(2)}\left(t, i, \mathbf{i}_{t}, \mathbf{l}_{t}\right)= & G_{x}^{(2)}\left(S(t) \gamma(t+1, i-N-1), V^{(2)}\left(x, t+1, n,\left\{\mathbf{l}_{t}, l_{t}+1\right\}\right), r\left(t+1, l_{t}+1\right) ; \mathbf{i}_{t}, \mathbf{l}_{t}\right) \\
& -G_{x}^{(2)}\left(S(t) \gamma(t+1, i-N-2), V^{(2)}\left(x, t+1, n,\left\{\mathbf{1}_{t}, l_{t}+1\right\}\right), r\left(t+1, l_{t}+1\right) ; \mathbf{i}_{t}, \mathbf{l}_{t}\right) \\
& -G_{x}^{(2)}\left(S(t) \gamma(t+1, i-N-1), 0, r\left(t+1, l_{t}+1\right) ; \mathbf{i}_{t}, \mathbf{l}_{t}\right) \\
& -G_{x}^{(2)}\left(S(t) \gamma(t+1, i-N-1), V^{(2)}\left(x, t+1, n,\left\{\mathbf{1}_{t}, l_{t}+1\right\}\right), r\left(t+1, l_{t}\right) ; \mathbf{i}_{t}, \mathbf{l}_{t}\right) \\
& +G_{x}^{(2)}\left(S(t) \gamma(t+1, i-N-2), 0, r\left(t+1, l_{t}+1\right) ; \mathbf{i}_{t}, \mathbf{l}_{t}\right) \\
& +G_{x}^{(2)}\left(S(t) \gamma(t+1, i-N-2), V^{(2)}\left(x, t+1, n,\left\{\mathbf{1}_{t}, l_{t}+1\right\}\right), r\left(t+1, l_{t}\right) ; \mathbf{i}_{t}, \mathbf{l}_{t}\right) \\
& +G_{x}^{(2)}\left(S(t) \gamma(t+1, i-N-1), 0, r\left(t+1, l_{t}\right) ; \mathbf{i}_{t}, \mathbf{1}_{t}\right) \\
& -G_{x}^{(2)}\left(S(t) \gamma(t+1, i-N-2), 0, r\left(t+1, l_{t}\right) ; \mathbf{i}_{t}, \mathbf{l}_{t}\right),
\end{aligned}
$$

for $i=N+1, \ldots, 2 N+1$,

$$
\begin{aligned}
e_{x}^{(2)}\left(t, i, \mathbf{i}_{t}, \mathbf{l}_{t}\right)= & G_{x}^{(2)}\left(S(t) \gamma(t+1, i-2 N-2), 0, r\left(t+1, l_{t}\right) ; \mathbf{i}_{t}, \mathbf{l}_{t}\right) \\
& -G_{x}^{(2)}\left(S(t) \gamma(t+1, i-2 N-3), 0, r\left(t+1, l_{t}\right) ; \mathbf{i}_{t}, \mathbf{l}_{t}\right),
\end{aligned}
$$


for $i=2 N+2, \ldots, 3 N+2$, and

$$
\begin{aligned}
e_{x}^{(2)}\left(t, i, \mathbf{i}_{t}, \mathbf{l}_{t}\right)= & G_{x}^{(2)}\left(S(t) \gamma(t+1, i-3 N-3), 0, r\left(t+1, l_{t}+1\right) ; \mathbf{i}_{t}, \mathbf{l}_{t}\right) \\
& -G_{x}^{(2)}\left(S(t) \gamma(t+1, i-3 N-4), 0, r\left(t+1, l_{t}+1\right) ; \mathbf{i}_{t}, \mathbf{l}_{t}\right) \\
& -G_{x}^{(2)}\left(S(t) \gamma(t+1, i-3 N-3), 0, r\left(t+1, l_{t}\right) ; \mathbf{i}_{t}, \mathbf{l}_{t}\right) \\
& +G_{x}^{(2)}\left(S(t) \gamma(t+1, i-3 N-4), 0, r\left(t+1, l_{t}\right) ; \mathbf{i}_{t}, \mathbf{l}_{t}\right),
\end{aligned}
$$

for $i=3 N+3, \ldots, 4 N+3$.

Consider now an equity-linked product that pays

$$
\left\{\begin{array}{l}
D(K(x)+1) \quad \text { if } K(x)=0,1, \ldots, n-1, \\
D(n) \quad \text { if } K(x) \geq n .
\end{array}\right.
$$

For notational convenience, we sometimes use $D\left(t, \mathbf{i}_{t}\right)$ to specify the index's realization.

Let $P^{(1)}\left(x, t, n, \mathbf{i}_{t}, \mathbf{1}_{t}\right)$ denote the premium at time $t$ of the equity-linked contract death benefit given that $(x)$ is still alive and the index and short-term rate processes have taken the path $\mathbf{i}_{t}$ and $\mathbf{l}_{t}$, respectively. With the martingale structure identified by (4.6), (4.7), (4.8), and (4.9), $P^{(1)}\left(x, t, n, \mathbf{i}_{t}, \mathbf{l}_{t}\right)$ may be obtained as the expected discounted payoffs

$$
P^{(1)}\left(x, t, n, \mathbf{i}_{t}, \mathbf{l}_{t}\right)=E_{x}^{(1)+}\left[\frac{D(K(x)+1) 1_{\{K(x)<n\}}}{B(K(x)+1)} B(t) \mid \mathbf{i}_{t}, \mathbf{1}_{t}, K(x) \geq t\right],
$$

where $E_{x}^{(1)+}[\cdot]$ represents the expectation with respect to $Q_{x}^{(1)+}$.

On the other hand, let $P^{(2)}\left(x, t, n, \mathbf{i}_{t}, \mathbf{1}_{t}\right)$ denote the premium at time $t$ of the equitylinked product accumulation benefit given that $(x)$ is still alive and the index process has taken the path $\mathbf{i}_{t}$. With the martingale structure identified by (4.10), (4.11), (4.12), and (4.13), $P^{(2)}\left(x, t, n, \mathbf{i}_{t}, \mathbf{l}_{t}\right)$ may be obtained as the expected discounted payoffs

$$
P^{(2)}\left(x, t, n, \mathbf{i}_{t}, \mathbf{1}_{t}\right)=E_{x}^{(2)+}\left[\frac{D(n) 1_{\{K(x) \geq n\}}}{B(n)} B(t) \mid \mathbf{i}_{t}, \mathbf{1}_{t}, K(x) \geq t\right] .
$$

Let $P\left(x, t, n, \mathbf{i}_{t}, \mathbf{l}_{t}\right)$ denote the premium at time $t$ of an $n$-year equity-linked product issue to $(x)$ with its payoff defined by (4.14). In particular, $P\left(x, 0, n, \mathbf{i}_{0}, \mathbf{1}_{0}\right)$ is the amount invested by an insured or, from insurers' point of view, the premium paid by the policyholder. We assume that $P\left(x, t, n, \mathbf{i}_{t}, \mathbf{1}_{t}\right)$ may be decomposed in two different premiums; $P^{(1)}\left(x, t, n, \mathbf{i}_{t}, \mathbf{l}_{t}\right)$ is the premium to cover the death benefit and $P^{(2)}\left(x, t, n, \mathbf{i}_{t}, \mathbf{1}_{t}\right)$ is the premium to cover the accumulation benefit. That is, we assume that

$$
P\left(x, t, n, \mathbf{i}_{t}, \mathbf{l}_{t}\right)=P^{(1)}\left(x, t, n, \mathbf{i}_{t}, \mathbf{l}_{t}\right)+P^{(2)}\left(x, t, n, \mathbf{i}_{t}, \mathbf{l}_{t}\right),
$$

where $P^{(1)}\left(x, t, n, \mathbf{i}_{t}, \mathbf{l}_{t}\right)$ and $P^{(2)}\left(x, t, n, \mathbf{i}_{t}, \mathbf{l}_{t}\right)$ are obtained using (4.15) and (4.16), respectively. 
An alternative approach is to evaluate equity-linked products containing death and accumulation benefits in a unified manner, using the pricing information from the endowment insurance products. In this case, the $n$-year equity-linked product premium $P\left(x, t, n, \mathbf{i}_{t}, \mathbf{1}_{t}\right)$ may be obtained as expected discounted payoffs

$$
P\left(x, t, n, \mathbf{i}_{t}, \mathbf{1}_{t}\right)=E_{x}^{(3)+}\left[\left(\frac{D(K(x)+1) 1_{\{K(x)<n-1\}}}{B(K(x)+1)}+\frac{D(n) 1_{\{K(x) \geq n-1\}}}{B(n)}\right) B(t) \mid \mathbf{i}_{t}, \mathbf{1}_{t}, K(x) \geq t\right] .
$$

Figure 4 presents the dynamic of the equity-linked premiums for time period $[t, t+1]$. Bear in mind that the first approach presented in this section evaluates equity-linked products by loading the death and survival probabilities separately. The second approach evaluates the equity-linked product using unified loaded probabilities.

\section{Evaluation of Equity-Linked Products}

In this section, we evaluate equity-linked contracts using recursive algorithms. It follows from (4.15) and (4.16) that

$$
\begin{aligned}
& P^{(1)}\left(x, t, n, \mathbf{i}_{t}, \mathbf{1}_{t}\right) \\
& =\frac{1}{1+r\left(t, l_{t}\right)}\left[\sum_{v=0}^{N}\left(e_{x}^{(1)}\left(t, v+2 N+2, \mathbf{i}_{t}, \mathbf{l}_{t}\right)+e_{x}^{(1)}\left(t, v+3 N+3, \mathbf{i}_{t}, \mathbf{l}_{t}\right)\right) D\left(t+1,\left\{\mathbf{i}_{t}, v\right\}\right)\right. \\
& +\sum_{v=0}^{N}\left(e_{x}^{(1)}\left(t, v, \mathbf{i}_{t}, \mathbf{l}_{t}\right) P^{(1)}\left(x, t+1, n,\left\{\mathbf{i}_{t}, v\right\},\left\{\mathbf{l}_{t}, l_{t}\right\}\right)\right. \\
& \left.\left.+e_{x}^{(1)}\left(t, v+N+1, \mathbf{i}_{t}, \mathbf{l}_{t}\right) P^{(1)}\left(x, t+1, n,\left\{\mathbf{i}_{t}, v\right\},\left\{\mathbf{1}_{t}, l_{t}+1\right\}\right)\right)\right],
\end{aligned}
$$

with $P^{(1)}\left(x, n, n, \mathbf{i}_{n}, \mathbf{1}_{n}\right)=0$ and

$$
\begin{aligned}
P^{(2)}\left(x, t, n, \mathbf{i}_{t}, \mathbf{1}_{t}\right)=\frac{1}{1+r\left(t, l_{t}\right)}[ & {\left[\sum _ { v = 0 } ^ { N } \left(e_{x}^{(2)}\left(t, v, \mathbf{i}_{t}, \mathbf{1}_{t}\right) P^{(2)}\left(x, t+1, n,\left\{\mathbf{i}_{t}, v\right\},\left\{\mathbf{1}_{t}, l_{t}\right\}\right)\right.\right.} \\
& \left.\left.+e_{x}^{(2)}\left(t, v+N+1, \mathbf{i}_{t}, \mathbf{1}_{t}\right) P^{(2)}\left(x, t+1, n,\left\{\mathbf{i}_{t}, v\right\},\left\{\mathbf{1}_{t}, l_{t}+1\right\}\right)\right)\right],
\end{aligned}
$$

with $P^{(2)}\left(x, n, n, \mathbf{i}_{n}, \mathbf{1}_{n}\right)=D\left(n, \mathbf{i}_{n}\right)$. 
Table 1: Point-to-point with term-end design for various interest rate volatilities.

\begin{tabular}{|c|c|c|c|c|c|c|c|c|c|c|c|}
\hline \multirow[b]{2}{*}{$\sigma$} & \multirow[b]{2}{*}{$\sigma_{r}(t)$} & \multirow[b]{2}{*}{$C^{I}$} & \multicolumn{6}{|c|}{ Decomposed approach } & \multicolumn{3}{|c|}{ Unified approach } \\
\hline & & & $C^{U}$ & $C^{D}$ & $C_{0.5}^{C J}$ & $C_{2}^{C J}$ & $C_{-0.1}^{G}$ & $C_{0.3}^{G}$ & $C^{I}$ & $C^{U}$ & $C^{D}$ \\
\hline \multicolumn{12}{|c|}{$3 \%$ Minimum guarantee on $90 \%$ premium } \\
\hline \multirow{3}{*}{$20 \%$} & $0 \%$ & 62.17 & 56.27 & 68.58 & 59.94 & 58.38 & 63.08 & 59.59 & 70.28 & 69.98 & 70.05 \\
\hline & $4 \%$ & 62.17 & 55.85 & 69.17 & 59.79 & 58.07 & 63.12 & 59.46 & 70.27 & 69.40 & 70.64 \\
\hline & $8 \%$ & 62.15 & 55.44 & 69.75 & 59.63 & 57.75 & 63.15 & 59.31 & 70.25 & 68.83 & 71.23 \\
\hline \multirow[t]{3}{*}{$30 \%$} & $0 \%$ & 48.95 & 43.20 & 55.15 & 47.02 & 45.63 & 49.79 & 46.54 & 55.46 & 55.14 & 55.25 \\
\hline & $4 \%$ & 48.95 & 42.93 & 55.54 & 46.93 & 45.43 & 49.82 & 46.45 & 55.45 & 54.74 & 55.68 \\
\hline & $8 \%$ & 48.94 & 42.66 & 55.93 & 46.83 & 45.23 & 49.85 & 46.37 & 55.45 & 54.35 & 56.11 \\
\hline \multicolumn{12}{|c|}{$3 \%$ Minimum guarantee on $100 \%$ premium } \\
\hline \multirow{3}{*}{$20 \%$} & $0 \%$ & 44.58 & 41.32 & 47.87 & 43.45 & 42.65 & 45.06 & 43.20 & 53.25 & 53.12 & 52.88 \\
\hline & $4 \%$ & 44.57 & 40.93 & 48.38 & 43.32 & 42.36 & 45.09 & 43.07 & 53.25 & 52.56 & 53.46 \\
\hline & $8 \%$ & 44.55 & 40.53 & 48.89 & 43.18 & 42.07 & 45.12 & 42.94 & 53.24 & 52.00 & 54.03 \\
\hline \multirow{3}{*}{$30 \%$} & $0 \%$ & 32.20 & 29.12 & 35.38 & 31.25 & 30.56 & 32.63 & 30.96 & 39.27 & 39.13 & 38.98 \\
\hline & $4 \%$ & 32.20 & 28.89 & 35.69 & 31.18 & 30.40 & 32.65 & 30.89 & 39.27 & 38.77 & 39.36 \\
\hline & $8 \%$ & 32.19 & 28.65 & 36.00 & 31.10 & 30.23 & 32.67 & 30.81 & 39.27 & 38.41 & 39.75 \\
\hline
\end{tabular}

A recursive formula to evaluate $P\left(x, t, n, \mathbf{i}_{t}, \mathbf{l}_{t}\right)$ under $Q_{x}^{(3)+}$ is determined using (4.18), that is,

$$
\begin{gathered}
P\left(x, t, n, \mathbf{i}_{t}, \mathbf{l}_{t}\right) \\
=\frac{1}{1+r\left(t, l_{t}\right)}\left[\sum_{v=0}^{N}\left(e_{x}^{(3)}\left(t, v+2 N+2, \mathbf{i}_{t}, \mathbf{l}_{t}\right)+e_{x}^{(3)}\left(t, v+3 N+3, \mathbf{i}_{t}, \mathbf{l}_{t}\right)\right) D\left(t+1,\left\{\mathbf{i}_{t}, v\right\}\right)\right. \\
+\sum_{v=0}^{N}\left(e_{x}^{(3)}\left(t, v, \mathbf{i}_{t}, \mathbf{l}_{t}\right) P^{(3)}\left(x, t+1, n,\left\{\mathbf{i}_{t}, v\right\},\left\{\mathbf{l}_{t}, l_{t}\right\}\right)\right. \\
\left.\left.+e_{x}^{(3)}\left(t, v+N+1, \mathbf{i}_{t}, \mathbf{l}_{t}\right) P\left(x, t+1, n,\left\{\mathbf{i}_{t}, v\right\},\left\{\mathbf{l}_{t}, l_{t}+1\right\}\right)\right)\right]
\end{gathered}
$$

for $t=0, \ldots, n-2$, where

$$
P\left(x, n-1, n, \mathbf{i}_{n-1}, \mathbf{1}_{n-1}\right)=\sum_{v=0}^{N} \frac{\pi\left(n, l_{n-1}\right)^{v}\left(1-\pi\left(n, l_{n-1}\right)\right)^{N-v}}{1+r\left(n-1, l_{n-1}\right)} D\left(n,\left\{\mathbf{i}_{n-1}, v\right\}\right) .
$$

Note that the surrender options for equity-linked products under stochastic interest rates are evaluated in Gaillardetz [27].

\section{Valuation of Equity-Indexed Annuities: Numerical Examples}

This section implements numerically the methods we developed previously by considering two types of equity-indexed annuities. They appeal to investors because they offer the same protection as conventional annuities by limiting the financial risk, but also provide 
participation in the equity market. From Lin and Tan [11] and Tiong [8], EIA designs may be generally grouped in two broad classes: Annual Reset and Point-to-Point. The index growth on an EIA with the former is measured and locked in each year. Particularly, the index growth with a term-end point design is calculated using the index value at the beginning and the end of each year. In the latter, the index growth is based on the growth between two time points over the entire term of the annuity. In the case of the term-end point design, the growth is evaluated using the beginning and ending values of the index. The cost of the EIA contract is reflected through the participation rate. Hence, the participation rate is expected to be lower for expensive designs.

Our examples involve five-year EIAs issued to a male-aged 55 with minimum interest rate guarantee of either $3 \%$ on $100 \%$ of the premium or $3 \%$ on $90 \%$ of the premium. For illustration purposes, we assume that the insurance product values, $V^{(j)}(x, 0, n)(j=1,2,3$ and $n=1,2,3,4,5)$, are determined using the standard deviation premium principle (see Bowers et al. [20]) with a loading factor of $5.00 \%$ based on the 1980 US CSO table (see http://www.soa.org/). We also assume that the short-term rate $r(t)$ follows the BDT where the volatility is either $0 \%, 4 \%$, or $8 \%$. The observed price of the zero-coupon bond $L(0, T)$ is assumed to be equal to $(1.05)^{-T}$ for $T=1,2, \ldots, 5$. Hence, the interest rate model may be calibrated using (2.6) and (2.7). For simplification purposes, the index will be governed by the Cox et al. [28] model where $S(0)=1$ and the number of trading dates $N$ is 3 . In this recombining model, the index at time $k S(k)$ has two possible outcomes at time $k+\Delta$ : it is either increasing to $S(k+\Delta)=U S(k)$ or decreasing to $S(k+\Delta)=d S(k)$. The increasing and decreasing factors $u$ and $d$ are supposed to be constant and are obtained from the volatility of the index $\sigma$. This volatility is assumed to be constant and is either $20 \%$ or $30 \%$. In other words, $u=e^{\sigma / \sqrt{N}}(\sigma=0.2,0.3)$ and $d=u^{-1}$. The index conditional martingale probability structure is obtained using (2.10). The conditional joint distribution of the interest rates and the insurance products are obtained using Propositions 3.1, 3.2, and 3.2. Here, these martingale probabilities are determined based on the implied insurance volatilities, which are derived numerically under the constraint given in (3.33).

The analysis is performed using the point-to-point and reset EIA classes with term-end point design.

\subsection{Point-to-Point}

We first consider one of the simplest classes of EIAs, known as the point-to-point. Their payoffs in year $t$ can be represented by

$$
D(t)=\max \left[\min \left[1+\alpha R(t),(1+\zeta)^{t}\right], \beta(1+g)^{t}\right],
$$

where $\alpha$ represents the participation rate and the "gain" $R(t)$ need to be defined depending on the design. It also provides a protection against the loss from a down market $\beta(1+g)^{t}$. The cap rate $(1+\zeta)^{t}$ reduces the cost of such contract since it imposes an upper bound on the maximum return.

As explained in Lin and Tan [11], an EIA is evaluated through its participation rate $\alpha$. Without loss of generality, we suppose that the initial value of EIA contracts is one monetary unit. The present value of the EIA is a function of the participation rate through the payoff function $D$. We then solve numerically for $\alpha$, the critical participation rate, such 
Table 2: Point-to-point with term-end design and 15\% cap rate for various interest rate volatilities.

\begin{tabular}{|c|c|c|c|c|c|c|c|c|c|c|c|}
\hline & & & \multicolumn{6}{|c|}{ Decomposed approach } & \multicolumn{3}{|c|}{ Unified approach } \\
\hline$\sigma$ & $\sigma_{r}(t)$ & $C^{I}$ & $C^{U}$ & $C^{D}$ & $C_{0.5}^{C J}$ & $C_{2}^{C J}$ & $C_{-0.1}^{G}$ & $C_{0.3}^{G}$ & $C^{I}$ & $C^{u}$ & $C^{D}$ \\
\hline \multicolumn{12}{|c|}{$3 \%$ Minimum guarantee on $90 \%$ premium } \\
\hline \multirow{3}{*}{$20 \%$} & $0 \%$ & 65.65 & 59.00 & 72.98 & 62.95 & 61.16 & 66.69 & 62.73 & 75.95 & 76.61 & 75.43 \\
\hline & $4 \%$ & 65.65 & 58.61 & 73.40 & 62.82 & 60.88 & 66.72 & 62.62 & 75.95 & 76.10 & 75.85 \\
\hline & $8 \%$ & 65.64 & 58.23 & 73.85 & 62.68 & 60.61 & 66.75 & 62.50 & 75.94 & 75.64 & 76.29 \\
\hline \multirow{3}{*}{$30 \%$} & $0 \%$ & 58.94 & 51.26 & 67.42 & 55.97 & 54.00 & 60.11 & 55.62 & 69.87 & 70.94 & 69.33 \\
\hline & $4 \%$ & 58.94 & 51.10 & 67.54 & 55.91 & 53.89 & 60.12 & 55.59 & 69.88 & 70.66 & 69.52 \\
\hline & $8 \%$ & 58.94 & 50.96 & 67.70 & 55.86 & 53.79 & 60.13 & 55.56 & 69.90 & 70.45 & 69.76 \\
\hline \multicolumn{12}{|c|}{$3 \%$ Minimum guarantee on $100 \%$ premium } \\
\hline \multirow{3}{*}{$20 \%$} & $0 \%$ & 45.20 & 41.85 & 48.58 & 44.00 & 43.18 & 45.69 & 43.78 & 54.60 & 54.93 & 54.10 \\
\hline & $4 \%$ & 45.19 & 41.44 & 49.07 & 43.87 & 42.89 & 45.72 & 43.66 & 54.60 & 54.35 & 54.63 \\
\hline & $8 \%$ & 45.17 & 41.03 & 49.56 & 43.73 & 42.59 & 45.74 & 43.52 & 54.59 & 53.80 & 55.16 \\
\hline \multirow{3}{*}{$30 \%$} & $0 \%$ & 34.25 & 30.86 & 37.78 & 33.12 & 32.34 & 34.73 & 32.87 & 43.20 & 43.99 & 42.60 \\
\hline & $4 \%$ & 34.25 & 30.63 & 38.04 & 33.06 & 32.19 & 34.75 & 32.81 & 43.20 & 43.46 & 42.96 \\
\hline & $8 \%$ & 34.25 & 30.40 & 38.31 & 32.99 & 32.04 & 34.77 & 32.74 & 43.21 & 42.97 & 43.45 \\
\hline
\end{tabular}

that $P\left(x, 0, n, \mathbf{i}_{0}, \mathbf{1}_{0}\right)=1$, where $P\left(x, 0, n, \mathbf{i}_{0}, \mathbf{1}_{0}\right)$ is obtained using (4.17) for the first approach or using (4.18) for the second approach by holding all other parameter values constant.

\subsubsection{Term-End Point}

In practice, various designs for $R(t)$ have been proposed. The term-end point design is the simplest crediting method. It measures the index growth from the start to the end of a term. The index on the day the contract is issued is taken as the starting index, and the index on the day the policy matures or the time of death is taken as the ending index. Hence, the "gain" provided by the point-to-point EIA with term-end point may expressed as

$$
R(t)=\frac{S(t)}{S(0)}-1
$$

The EIA payoff given in (6.1) is defined by

$$
D\left(t, \mathbf{i}_{t}\right)=\max \left[\min \left[1+\alpha\left(\prod_{l=0}^{t} \gamma\left(l, i_{l}\right)-1\right),(1+\zeta)^{t}\right], \beta(1+g)^{t}\right] .
$$

Tables 1 and 2 give the critical participation rates based on (5.1) and (5.2) for the decomposed approach as well as (5.3) for the unified approach over different short-term rate volatilities $(0 \%, 4 \%$, and $8 \%)$. The index volatility is set to either $20 \%$ or $30 \%$. We present the participation rates of 5-year EIA contracts with the term-end design without cap rate $(\zeta=\infty)$ in Table 1 and $15 \%$ cap rate in Table 2 . We consider two types of minimum guarantees: $\beta=90 \%$ and $\beta=100 \%$ and both with $g=3 \%$.

The participation rates obtained for $\sigma_{r}(t)=0 \%$ are consistent with the corresponding participation rates under deterministic interest rates presented in Gaillardetz and Lin [13]. 
Table 3: Annual reset with term-end point design for various interest rate volatilities.

\begin{tabular}{|c|c|c|c|c|c|c|c|c|c|c|c|}
\hline \multirow[b]{2}{*}{$\sigma$} & \multirow[b]{2}{*}{$\sigma_{r}(t)$} & \multirow[b]{2}{*}{$C^{I}$} & \multicolumn{6}{|c|}{ Decomposed approach } & \multicolumn{3}{|c|}{ Unified approach } \\
\hline & & & $C^{U}$ & $C^{D}$ & $C_{0.5}^{C J}$ & $C_{2}^{C J}$ & $C_{-0.1}^{G}$ & $C_{0.3}^{G}$ & $C^{I}$ & $C^{u}$ & $C^{D}$ \\
\hline \multicolumn{12}{|c|}{$3 \%$ Minimum guarantee on $90 \%$ premium } \\
\hline \multirow{3}{*}{$20 \%$} & $0 \%$ & 38.91 & 37.19 & 40.51 & 38.42 & 38.02 & 39.16 & 38.19 & 43.26 & 43.25 & 43.27 \\
\hline & $4 \%$ & 38.91 & 37.27 & 40.41 & 38.44 & 38.07 & 39.15 & 38.21 & 43.26 & 43.31 & 43.21 \\
\hline & $8 \%$ & 38.91 & 37.35 & 40.32 & 38.46 & 38.12 & 39.14 & 38.23 & 43.27 & 43.37 & 43.17 \\
\hline \multirow{3}{*}{$30 \%$} & $0 \%$ & 28.23 & 26.72 & 29.59 & 27.86 & 27.54 & 28.42 & 27.65 & 31.39 & 31.38 & 31.39 \\
\hline & $4 \%$ & 28.23 & 26.79 & 29.50 & 27.88 & 27.59 & 28.41 & 27.67 & 31.39 & 31.43 & 31.34 \\
\hline & $8 \%$ & 28.23 & 26.87 & 29.41 & 27.89 & 27.63 & 28.41 & 27.69 & 31.39 & 31.50 & 31.30 \\
\hline \multicolumn{12}{|c|}{$3 \%$ Minimum guarantee on $100 \%$ premium } \\
\hline \multirow{3}{*}{$20 \%$} & $0 \%$ & 35.42 & 33.93 & 36.74 & 35.04 & 34.71 & 35.62 & 34.82 & 40.59 & 40.57 & 40.55 \\
\hline & $4 \%$ & 35.42 & 33.92 & 36.76 & 35.03 & 34.70 & 35.62 & 34.82 & 40.59 & 40.52 & 40.60 \\
\hline & $8 \%$ & 35.41 & 33.90 & 36.77 & 35.02 & 34.69 & 35.61 & 34.81 & 40.59 & 40.49 & 40.66 \\
\hline \multirow{3}{*}{$30 \%$} & $0 \%$ & 25.19 & 23.87 & 26.36 & 24.91 & 24.65 & 25.35 & 24.71 & 28.89 & 28.86 & 28.87 \\
\hline & $4 \%$ & 25.19 & 23.88 & 26.34 & 24.91 & 24.66 & 25.35 & 24.72 & 28.89 & 28.85 & 28.89 \\
\hline & $8 \%$ & 25.19 & 23.89 & 26.32 & 24.91 & 24.67 & 25.34 & 24.72 & 28.90 & 28.85 & 28.91 \\
\hline
\end{tabular}

As expected, the participation rates for the independent copulas decrease as the interest rate volatility increases; however, this effect is negligible for 5-year contracts.

The independent copula may be obtained by letting $\kappa \rightarrow 0$ in the Cook-Johnson copula. Similarly, the Frechet-Hoeffding upper bound is obtained by letting $\kappa \rightarrow \infty$. This explains that the participation rates with $\kappa(t)=0.5$ are closer to the independent one than the participation rates obtained using $\kappa(t)=2$, which are closer to the upper copula. Setting $\kappa(t)=0$ in the Gaussian copula also leads to the independent copula. The participation rates are between the independent copula and the lower copula when $\mathcal{\kappa}(t)=-0.1$. On the other hand, when $\kappa(t)=0.3$ the participation rates are between the independent copula and the upper copula.

The width of participation rate bands for the decomposed approach increases as the short-term rate volatility increases. Here, the participation rate band represents the difference between the participation rates obtained from the lower copula and the upper copula. Indeed, the participation rate for the upper copula $(\beta=90 \%$ and $\sigma=20 \%$ ) decreases from $56.27 \%$ $\left(\sigma_{r}(t)=0 \%\right)$ to $55.44 \%\left(\sigma_{r}(t)=8 \%\right)$, meanwhile under the lower copula the participation rate passes from $68.58 \%\left(\sigma_{r}(t)=0 \%\right)$ to $69.75 \%\left(\sigma_{r}(t)=0 \%\right)$. This is due to the fact that increasing $\sigma_{r}$ introduces more uncertainty in the model.

As we increase the volatility of the index, the participation rate decreases since a higher volatility leads to more valuable embedded financial options. As expected, the participation rates for $\beta=100 \%$ are lower than the corresponding values with $\beta=90 \%$.

The dependence effects for the unified approach are negligible since there is a natural "hedging" between the death and accumulation benefits. The introduction of stochastic interest rates has more impact when $\beta=90 \%$ than when $\beta=100 \%$ because the participation rates are higher. Although the participation rates are higher when $\sigma=20 \%$, the dependence has relatively more impact if $\sigma=30 \%$ because the model is more risky.

As expected, imposing a ceiling on the equity return that can be credited increases the participation rates. Furthermore, the magnitude of the increments is more significant 
Table 4: Annual reset with term-end point design and 15\% cap rate for various interest rate volatilities.

\begin{tabular}{|c|c|c|c|c|c|c|c|c|c|c|c|}
\hline \multirow[b]{2}{*}{$\sigma$} & \multirow[b]{2}{*}{$\sigma_{r}(t)$} & \multirow[b]{2}{*}{$C^{I}$} & \multicolumn{6}{|c|}{ Decomposed Approach } & \multicolumn{3}{|c|}{ Unified Approach } \\
\hline & & & $C^{U}$ & $C^{D}$ & $C_{0.5}^{C J}$ & $C_{2}^{C J}$ & $C_{-0.1}^{G}$ & $C_{0.3}^{G}$ & $C^{I}$ & $C^{U}$ & $C^{D}$ \\
\hline \multicolumn{12}{|c|}{$3 \%$ Minimum Guarantee on $90 \%$ Premium } \\
\hline \multirow{3}{*}{$20 \%$} & $0 \%$ & 42.49 & 38.58 & 45.86 & 41.35 & 40.44 & 43.04 & 40.86 & 52.63 & 52.62 & 52.65 \\
\hline & $4 \%$ & 42.49 & 38.78 & 45.65 & 41.39 & 40.56 & 43.02 & 40.91 & 52.64 & 52.76 & 52.53 \\
\hline & $8 \%$ & 42.49 & 38.98 & 45.44 & 41.44 & 40.69 & 43.00 & 40.97 & 52.66 & 52.91 & 52.44 \\
\hline \multirow{3}{*}{$30 \%$} & $0 \%$ & 35.80 & 33.10 & 38.12 & 35.02 & 34.40 & 36.18 & 34.69 & 42.82 & 42.80 & 42.83 \\
\hline & $4 \%$ & 35.81 & 33.28 & 37.93 & 35.06 & 34.50 & 36.17 & 34.73 & 42.83 & 42.94 & 42.72 \\
\hline & $8 \%$ & 35.81 & 33.47 & 37.75 & 35.09 & 34.60 & 36.16 & 34.78 & 42.84 & 43.09 & 42.62 \\
\hline \multicolumn{12}{|c|}{ 3\% Minimum Guarantee on $100 \%$ Premium } \\
\hline \multirow{3}{*}{$20 \%$} & $0 \%$ & 35.42 & 33.93 & 37.69 & 35.04 & 34.71 & 35.62 & 34.82 & 47.46 & 47.45 & 47.35 \\
\hline & $4 \%$ & 35.42 & 33.92 & 37.73 & 35.03 & 34.70 & 35.62 & 34.82 & 47.46 & 47.36 & 47.46 \\
\hline & $8 \%$ & 35.41 & 33.90 & 37.77 & 35.02 & 34.69 & 35.61 & 34.81 & 47.47 & 47.28 & 47.60 \\
\hline \multirow{3}{*}{$30 \%$} & $0 \%$ & 30.40 & 27.60 & 32.72 & 29.73 & 29.17 & 30.75 & 29.36 & 39.41 & 39.45 & 39.34 \\
\hline & $4 \%$ & 30.40 & 27.63 & 32.66 & 29.74 & 29.19 & 30.75 & 29.37 & 39.42 & 39.45 & 39.36 \\
\hline & $8 \%$ & 30.40 & 27.67 & 32.62 & 29.75 & 29.22 & 30.74 & 29.38 & 39.43 & 39.48 & 39.40 \\
\hline
\end{tabular}

in a high volatility market. This is because the effect of the volatility diminishes as the cap rate decreases and hence the behavior of the EIA payoff is similar for different ranges of volatilities. This is particularly observable when $\beta=90 \%$.

\subsection{Annual Reset}

We now consider the most popular class of EIAs, known as the annual reset. They appeal to investors because they offer similar features as the point-to-point class; however, the interest credited to a annual reset EIA contract cannot be lost. This "lock-in" feature protects the investor against a poor performance of the index over a particular year. The payoff of this type of EIA contracts is defined by

$$
D(t)=\max \left[\prod_{l=1}^{t} \max [\min [1+\alpha R(l)-v,(1+\zeta)], 1], \beta(1+g)^{t}\right],
$$

where $R(l)$ represents the realized "gain" in year $l$, which varies from product to product.

The cases where $v$ is set to 0 are known as annual reset EIAs and the cases where $v>0$ are known as annual yield spreads. Furthermore, the participation levels in those cases $v>0$ are typically $100 \%$. As mentioned previously, in the case of annual reset, we fix $v=0$ and determine the critical participation rate $\alpha$ while fixing $g, \beta$, and $\zeta$. In the traditional yield spread $v$ needs to be determined such that the cost of EIA embedded options is covered by the initial premium while fixing $\alpha=100 \%, g, \beta$, and $\zeta$. 


\subsubsection{Term-End Point}

In the case of annual reset EIA with term-end point, the index return is calculated each year by comparing the indices at the beginning and ending policy anniversaries. Hence, the participation rate may be expressed as

$$
R(t)=\frac{S(t)}{S(t-1)}-1
$$

In this case, the EIA payoff given in (6.4) is defined by

$$
D\left(t, \mathbf{i}_{t}\right)=\max \left[\prod_{l=1}^{t} \max \left[\min \left[1+\alpha\left(\gamma\left(l, i_{l}\right)-1\right)-v,(1+\zeta)\right], 1\right], \beta(1+g)^{t}\right] .
$$

Tables 3 and 4 consider an annual reset EIA with term-end point design for various cap rates $(\zeta=\infty$ and $\zeta=15 \%)$. In this numerical illustration, we consider the same set of parameters; particularly, the short-term rate volatility is either equal to $0 \%, 4 \%$, or $8 \%$ and the index volatility is set to either $20 \%$ or $30 \%$ with $N=3$. We find $\alpha$ such that (4.17) for the decomposed approach and (4.18) for the unified approach are equal to 1 by setting $v=0 \%$.

The annual reset with term-end point design is more expensive than the point-topoint with the term-end point design. The participation rates from the upper copula increase while the ones from the lower copula decrease as $\sigma_{r}(t)$ increases for both approaches when $\beta=90 \%$. This leads to narrower participation rate bands for the decomposed approach. These behaviors are inverted for $\beta=100 \%$. In that case, it leads to wider participation rate bands for the decomposed approach. The imposition of a $15 \%$ cap rate may increase the participation rate as much as $10 \%$. However, there is no impact on the participation rate under the decomposed approach when $\sigma=20 \%$ and $\beta=100 \%$.

\section{Conclusions}

The purpose of this paper is to generalize the approach presented by Gaillardetz and Lin [13] under stochastic interest rates. To this end, martingale probability measures for each of the term life, pure endowment, and endowment insurances are introduced under stochastic interest rates. Using the insurance market information, we obtain equity-linked martingale measures that combined the insurance, interest rates, and index information. Although the choice of copulas is somewhat arbitrary, with additional premium information from certain equity-linked products, we would be able to narrow down the choices. We present two different pricing approaches for equity-linked products. The first approach evaluates death benefits and accumulation/survival benefits separately. In the second approach, we evaluate the death benefits and the survival benefits in a unified manner by using the endowment insurance products to define the martingale measure. A detailed numerical analysis is then performed for existing EIAs in the North American market.

Our methodology may be used to evaluate variable annuities (segregated fund contracts in Canada) because of the similarity in payoff structure between EIAs and VAs. Furthermore, our approach may also be used to evaluate Universal Life insurances, variable Universal Life insurances, and others equity-linked products. 


\section{Acknowledgments}

This research was supported by the Natural Sciences and Engineering Research Council of Canada and a Ph. D. grant from the Casualty Actuarial Society and the Society of Actuaries. The author is very grateful to Professor X. Sheldon Lin for his valuable comments and suggestions.

\section{Endnotes}

1. Utility theory is also used to price standard life insurance products.

\section{References}

[1] M. R. Hardy, Investment Guarantees: Modeling and Risk Management for Equity- Linked Life Insurance, John Wiley \& Sons, Hoboken, NJ, USA, 2003.

[2] M. J. Brennan and E. S. Schwartz, "The pricing of equity-linked life insurance policies with an asset value guarantee," Journal of Financial Economics, vol. 3, pp. 195-213, 1976.

[3] P. Boyle and E. Schwartz, "Equilibrium prices of equity linked insurance policies with an asset value guarantee," Journal of Risk and Insurance, vol. 44, pp. 639-660, 1977.

[4] A. R. Bacinello and F. Ortu, "Pricing guaranteed securities-linked life insurance under interest-rate risk," in Proceedings of the 3rd AFIR International Colloquium on Actuarial Approach For Financial Risks, pp. 35-55, Rome, Italy, April 1993.

[5] A. R. Bacinello and F. Ortu, "Single and periodic premiums for guaranteed equitylinked life insurance under interest-rate risk: the "lognormal + Vasicek" case," in Financial Modelling, pp. 1-25, Physica, Berlin, Germany, 1994.

[6] T. Møller, "Risk-minimizing hedging strategies for unit-linked life insurance contracts," Astin Bulletin, vol. 28, no. 1, pp. 17-47, 1998.

[7] V. R. Young and T. Zariphopoulou, "Pricing dynamic insurance risks using the principle of equivalent utility," Scandinavian Actuarial Journal, no. 4, pp. 246-279, 2002.

[8] S. Tiong, "Valuing equity-indexed annuities," North American Actuarial Journal, vol. 4, no. 4, pp. 149$163,2000$.

[9] H. Lee, "Pricing equity-indexed annuities with path-dependent options," Insurance: Mathematics $\mathcal{E}$ Economics, vol. 33, no. 3, pp. 677-690, 2003.

[10] K. S. Moore, “Optimal surrender strategies for equity-indexed annuity investors," Insurance: Mathematics \& Economics, vol. 44, no. 1, pp. 1-18, 2009.

[11] X. S. Lin and K. S. Tan, "Valuation of equity-Indexed annuities under stochastic interest rate," North American Actuarial Journal, vol. 7, no. 3, pp. 72-91, 2003.

[12] M. Kijima and T. Wong, "Pricing of ratchet equity-indexed annuities under stochastic interest rates," Insurance: Mathematics \& Economics, vol. 41, no. 3, pp. 317-338, 2007.

[13] P. Gaillardetz and X. S. Lin, "Valuation of equity-linked insurance and annuity products with binomial models," North American Actuarial Journal, vol. 10, no. 4, pp. 117-144, 2006.

[14] M.V. Wüthrich, H. Bühlmann, and H. Furrer, Market-Consistent Actuarial Valuation, EAA Lecture Notes, Springer, Berlin, Germany, 2008.

[15] P. Gaillardetz, "Valuation of life insurance products under stochastic interest rates," Insurance: Mathematics \& Economics, vol. 42, no. 1, pp. 212-226, 2008.

[16] H. H. Panjer, et al., Financial Economics with Applications to Investment, Insurance and Pensions, The Actuarial Foundation, Schaumburg, Ill, USA, 1998.

[17] X. S. Lin, Introductory Stochastic Analysis for Finance and Insurance, Wiley Series in Probability and Statistics, John Wiley \& Sons, Hoboken, NJ, USA, 2006.

[18] F. Black, E. Derman, and W. Toy, "A one-factor model of interest rates and its application to treasury bond options," Financial Analysts Journal, vol. 46, pp. 33-39, 1990.

[19] J. Hull and A. White, "Numerical procedures for implementing term structure models I: single-factor models," Journal of Derivatives, vol. 2, no. 1, p. 716. 
[20] N. L. Bowers Jr., U. G. Hans, J. C. Hickman, D. A. Jones, and Nesbitt, Actuarial Mathematics, Society of Actuaries, Schaumburg, Ill, USA, 2nd edition, 1997.

[21] H. Joe, Multivariate Models and Dependence Concepts, vol. 73 of Monographs on Statistics and Applied Probability, Chapman and Hall, London, UK, 1997.

[22] R. B. Nelsen, An Introduction to Copulas, vol. 139 of Lecture Notes in Statistics, Springer, New York, NY, USA, 1999.

[23] E. W. Frees and E. A. Valdez, “Understanding relationships using copulas,” North American Actuarial Journal, vol. 2, no. 1, pp. 1-25, 1998.

[24] S. Wang, "Aggregation of correlated risk portfolios: models and algorithms," in Proceedings of Casualty Actuarial Society, pp. 848-939, Arlington, Va, USA, 1998.

[25] G. G. Venter, "Tails of copulas," in Proceedings of Casualty Actuarial Society, pp. 68-113, 2000.

[26] G. Cherubini, E. Luciano, and W. Vecchiato, Copula Methods in Finance, Wiley Finance Series, John Wiley \& Sons, Chichester, UK, 2004.

[27] P. Gaillardetz, Equity-linked annuities and insurances, Ph.D. thesis, University of Toronto, Toronto, Ontario, Canada, 2006.

[28] J. C. Cox, S. A. Ross, and M. Rubinstein, “Option pricing: a simplified approach," Journal of Financial Economics, vol. 7, no. 3, pp. 229-263, 1979. 


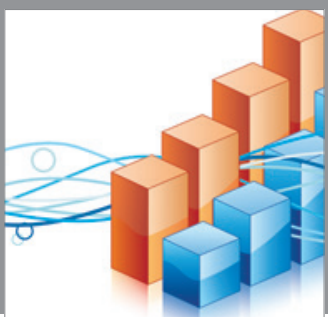

Advances in

Operations Research

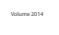

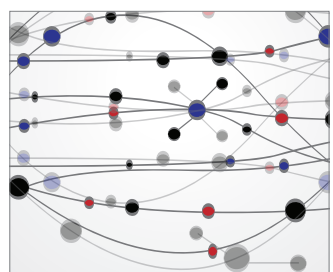

\section{The Scientific} World Journal
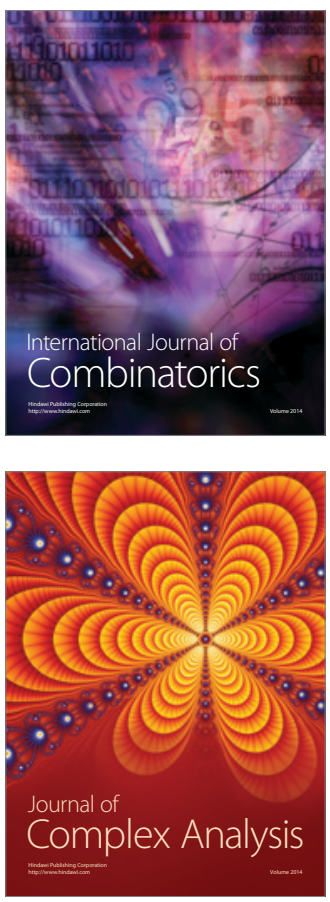

International Journal of

Mathematics and

Mathematical

Sciences
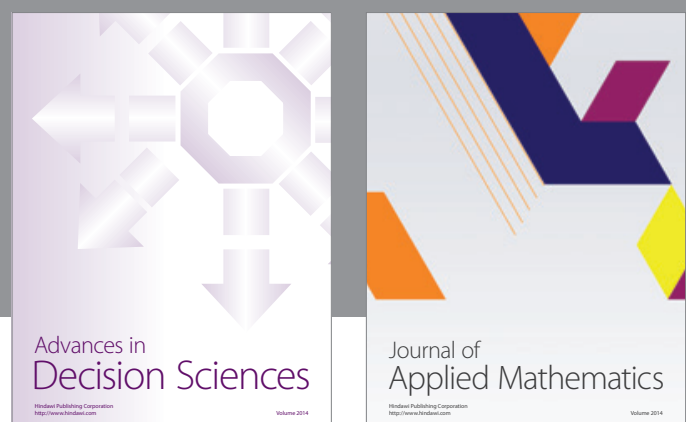

Journal of

Applied Mathematics
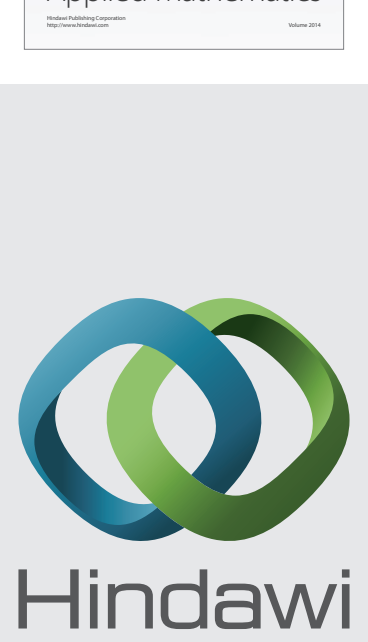

Submit your manuscripts at http://www.hindawi.com
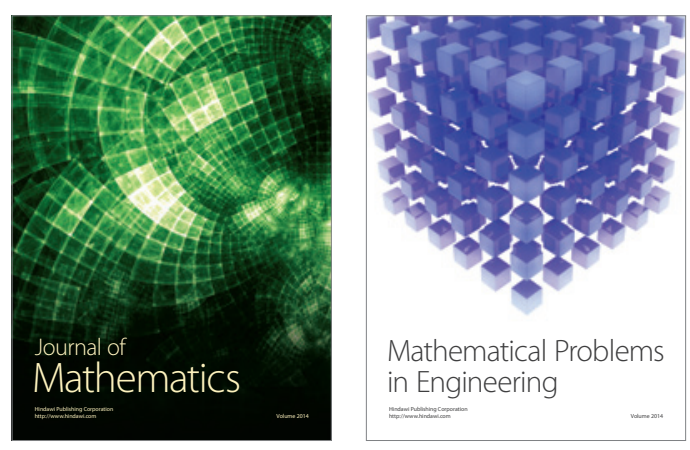

Mathematical Problems in Engineering
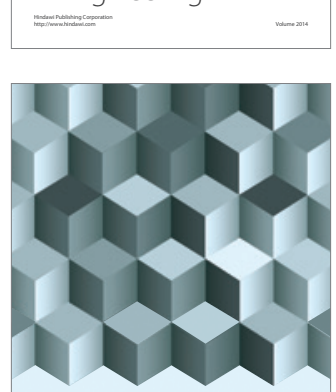

Journal of

Function Spaces
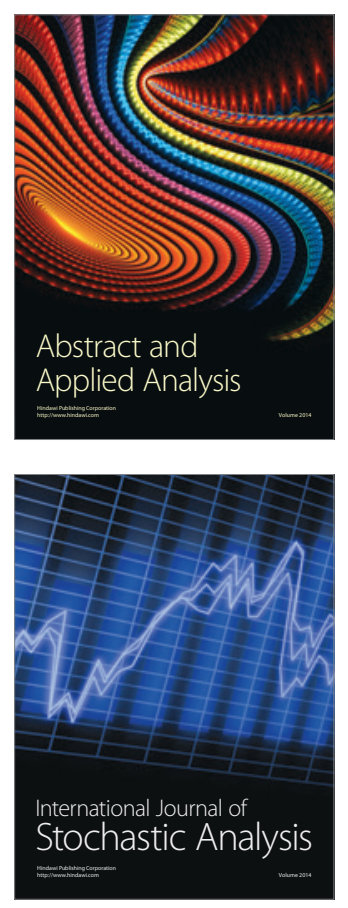

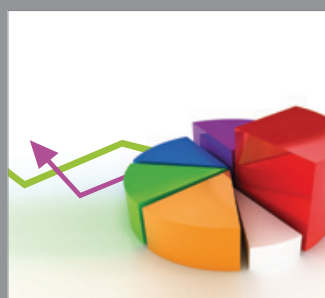

ournal of

Probability and Statistics

Promensencen
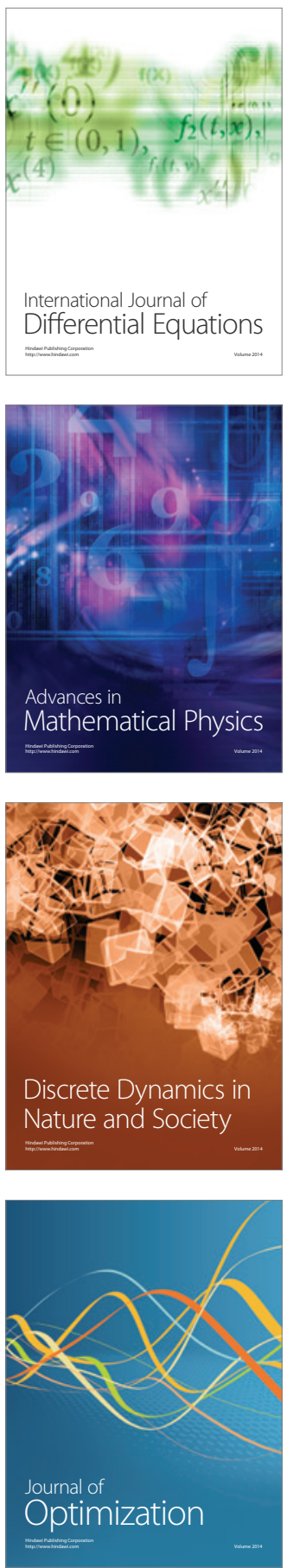